\title{
Steam condensation simulation in a scaled IRWST-ADS simulator with GOTHIC 8.1
}

\author{
Samanta Estévez-Albujaa , Gonzalo Jimeneza,", Suleiman Al Issab, Rafael Macián-Juanb, Kevin Fernández- \\ Cosialsa , César Queral ${ }^{\mathbf{a}}$ \\ ${ }^{a}$ Universidad Politécnica de Madrid, c/José Gutiérrez Abascal, 2, 28006 Madrid, Spain \\ ${ }^{b}$ Institute of Nuclear Engineering Faculty of Mechanical Engineering, Technische Universität München (TUM), Boltzmann Strasse 15, 85748 Garching b. Muenchen, \\ Germany
}

\section{A B S T R A C T}

The AP1000 ${ }^{\circ}$ advanced reactor passive safety systems are based on natural phenomena to ensure the con-tainment integrity during an accident. One of the most important passive systems is the Passive Core Cooling System (PXS) which includes the In-containment Refueling Water Storage Tank (IRWST), a pool that serves as a heat sink for the Passive Residual Heat Removal Heat Exchanger (PRHR) and the Automatic Depressurization System (ADS).

The thermal-hydraulic behavior of the pool is quite complex under accidental conditions: the pool receives steam at high velocity and temperature from the Reactor Cooling System (RCS), the pool is the heat sink of the PRHR, and eventually, it is the source for the low pressure safety injection. In order to study the behavior of the AP1000 IRWST during a steam discharge from the ADS at different stages of a SBLOCA, an experimental test rig was constructed in cooperation with the Technical University of Munich (TUM). The results obtained in the IRWST-ADS experiment were used to test the capability of GOTHIC 8.1 to simulate the phenomena observed experiments such as thermal stratification, direct contact condensation, and flashing. The GOTHIC model is based on two control volumes, one represents the channel test and the other the laboratory room. These control volumes are connected with a 3D-Connector between each other and with flow-paths to the boundary condi-tions. Pressure boundary conditions has been applied to the laboratory room control volume to maintain a constant pressure and temperature. Simulations were able to reproduce major occurring phenomena. Thermal stratification and flashing were predicted plausibly, however the direct contact condensation of steam and void fraction distribution are not perfectly simulated probably because of the selected mesh size. A sensitivity analysis has been conducted to the discretization scheme, the turbulence model, and the heat transfer correlation in order to test their effect upon GOTHIC model simulation.

\section{Introduction}

The use of suppression pools to limit the pressure increase in Nuclear Power Plant (NPP) containments has been a common strategy since the development of the first BWR. The Generation III + PWR re actors design normally include a suppression pool; as AP1000 ${ }^{\circ}$ (Westinghouse), EPR (AREVA) and APR1400 (KEPCO). Within this context of new reactor designs, the Westinghouse AP1000 implements passive safety systems to provide core cooling in case of accidental conditions. Unlike typical safety systems of conventional PWRs, these systems rely on natural phenomena such as gravity or natural circula tion. In the case of a Loss Of Coolant Accident (LOCA), the Passive Core Cooling System (PXS) is used to maintain the core cooled. This system includes an Automatic Depressurization System (ADS) with four stages which allows a slow and controlled pressure reduction of the primary Reactor Coolant System (RCS). The ADS discharges into the In con tainment Refueling Water Storage Tank (IRWST) where the injected steam is condensed (Westinghouse Electric Company LLC, 2009).

The capability of Computational Fluid Dynamics (CFD) codes to evaluate the steam direct contact condensation and the thermal mixing in a pool has been assessed by several research groups in the past. As an example, the researchers from Technical Research Centre of Finland (VTT) have simulated many experimental series performed at POOLEX and PPOOLEX with the codes GOTHIC, ANSYS Fluent and STAR CCM + . Those experimental series try to reproduce the steam injection condition in the Nordic BWR suppression pools through blowdown

\footnotetext{
* Corresponding author.

E-mail address: gonzalo.jimenez@upm.es (G. Jimenez).
} 
pipes. The experiments vary from low steam velocity injection (STB 20) to high steam velocity injection (STB 17), or even multiple blowdown pipe interaction. This references are available in the NKS webpage (Nordic Nuclear Safety Research (NKS), n.d.), see for example (Timperi et al., 2006) or (Pättikangas et al., 2009).

It is possible to find another example in (Kang and Song, 2008). In this work the thermal mixing in a subcooled water pool, representing the APR1400 IRWST, was studied using a lumped parameters volume model for the condensation region using CFD code CFX 4.4. Moon et al. (2009) modeled the steam discharge through a sparger and studied the overall pool behavior using the Steam Condensation Region Model (SCRM) with CFX 11.

Besides, the analysis of a turbulent jet flow induced by a steam jet discharged into a subcooled pool has also been performed, and the results do not show good agreement with the experimental data in terms of local phenomena (Kang and Song, 2010).

These works show that CFD codes are suitable to reproduce the important phenomena in a suppression pool. However, many questions arise when a full containment simulation during an accident is faced. The computational challenge is remarkable, as the containment building is very large with around $60,000 \mathrm{~m}^{3}$ of free volume and en closes a complex internal geometry. At the same time, the physical length scales needed to reproduce the physical phenomena (wall fric tion, convection and condensation) are small. To overcome this pro blem, the containment codes with 3D capabilities comes to play. In these codes, such as GOTHIC or GASFLOW, the RANS approach is used, including turbulence models. At the same time, the wall phenomen ology is simulated using correlations for friction, convection and con densation. This combination allows to simulate a full containment ac cident with enough accuracy and affordable computational cost.

In this paper, the GOTHIC 8.1 code is used (EPRI, 2014). As men tioned above, the GOTHIC code has the capability to model the con tainment in detail and calculate the three dimensional distribution Mass and Energy (M\&E). There is an extensive literature on the GOTHIC code validation in predicting 2D 3D phenomena under Design Basis Accidents (DBA) and Severe Accidents (SA). Regarding full containment phenomenology, the Carolina Virginia Tube Reactor (CVTR) DBA tests with a series of steam blowdown experiments that provide large scale containment response data. To assess the impact of subdivided versus lumped parameter modeling in the GOTHIC code, the CVTR tests were simulated with both types of models, as it can be seen in the GOTHIC 8.1 (QA) Qualification Report, section 19 (EPRI, 2014).

Furthermore, GOTHIC simulations of the two compartment geo metry of PANDA large scale thermal hydraulic facility model within the OECD SETH project, (Andreani et al., 2010) were successful in pre dicting gas distribution, wall heat transfer and condensation with a three dimensional model using a coarse mesh in commercial CFD standards. Another example of the evaluation of a GOTHIC model with a coarse mesh could be found in (Andreani and Paladino, 2010) con cluding that the code, with relatively coarse mesh relative to com mercial CFDs, can be used for predicting gas distribution in a complex, multi compartment geometry, with special attention to those regions where phenomena, such as stratification, incoming fluid stream, or condensing jet, take place.

GOTHIC has been also used to model the effect of direct contact steam condensation and other accompanying phenomena such as the thermal stratification and the mixing phenomena in a suppression pool during the activation of the ADS in order to evaluate safety related problems. Some of the POOLEX experiments have been successfully simulated by KTH researchers with the GOTHIC code, using a mo mentum and energy source model, which has been found adequate either for low and high steam injection rates, see (Gallego Marcos et al., 2016a,b, Li et al., 2014a,b, 2010, Li and Kudinov, 2015, 2009; Villanueva et al., 2015).

The Universidad Politécnica de Madrid (UPM) nuclear safety group simulated the STB 16 and STB 20 POOLEX experiments to obtain an adequate mesh for a model of a suppression pool in a BWR Mark III 3D GOTHIC model, concluding that thermal stratification phenomena could be simulated in GOTHIC for a wide range of meshing (Jimenez et al., 2015).

Ozdemir and George (2015) have also simulated POOLEX experi ments with GOTHIC 8.0 demonstrating that with an adequate meshing it is not necessary to use any alternative methods to model direct steam injection, steam condensation, and thermal stratification for low steam injections (as in STB 20 tests). They also performed also a Fukushima Daiichi Unit 1 containment analysis using a GOTHIC 3D model, being successful in capturing the three dimensional flow patterns in the suppression pool and the variations in the temperature concentration which influence the containment pressurization and hydrogen release (Ozdemir et al., 2015).

The nuclear safety group at the UPM is conducting a research line concerning the simulation of sequences and operator actuation for AP1000 reactor under DBA and SA conditions. The RCS and safety systems are modeled with TRACE and the containment is modeled with GOTHIC.

In a first step, the UPM simulated a set of SBLOCA sequences with TRACE code in order to evaluate the performance of passive systems (Project ISAMAR: Integrated Safety Assessment methodology applied to advanced reactors). The results agreed quite well with the Westinghouse ones calculated using NOTRUMP (Montero Mayorga et al., 2015). However, the 3D accurate simulation of the thermal hy draulic behavior of the IRWST was not possible with TRACE. In case of an ADS actuation in an AP1000, the steam is directly released into the IRWST from the pressurizer. The thermal hydraulic behavior of the IRWST is quite complex under these conditions: it receives steam at high velocities and temperatures from the RCS. The IRWST serves as the heat sink of the Passive Residual Heat Removal (PRHR) and the water reservoir for the low pressure safety injection system. The prediction of the IRWST thermal hydraulic behavior is crucial for the correct simu lation of the whole AP1000 containment under SBLOCA conditions.

Therefore, more data on the IRWST thermal hydraulic behavior under small break LOCA conditions was needed in order to determine the optimal modeling of the containment with GOTHIC. For this pur pose, an experimental test rig was constructed by the two phase flows laboratory of the Institute of Nuclear Engineering at the Technical University of Munich (TUM) (Al Issa et al., 2015) as the POOLEX and PPOOLEX tests available in the open literature did not represented the steam discharge of ADS spargers in the IRWST as they were designed to model a Olkiluoto type BWR containment suppression pool steam in jection without spargers.

In this paper, the GOTHIC results of an experiment done at the fa cility are presented. Firstly, the experimental set up and data are de scribed followed by the applied model. Secondly, a reference case was selected to show simulations results followed by a sensitivity analysis of the most relevant parameters. Thirdly, these results are compared to the experimental ones, and the influence of each parameter of the sensi tivity analysis is presented.

\section{Experimental TUM facility and data}

The TUM facility has been designed to reproduce the steam injec tion of the ADS in the IRWST. In the AP1000, the steam and water from the RCS are discharged in the IRWST from two spargers which have four cruciform branch arms inclined downward, and in each there are 174 holes. In this experiment the test section volume is selected to be proportional to one hole, dividing the IRWST total volume by the total number of sparger holes.

On the whole, the experimental facility consists of the test channel, a steam generator, and an automatic control unit to set the steam mass flow rate at a specific value, see Fig. 1 . The test section consists of a $2.5 \mathrm{~m}$ high, $0.15 \times 0.15 \mathrm{~m}$ rectangular channel with $0.01 \mathrm{~m}$ wall thickness. The channel is made of a transparent polycarbonate, which 

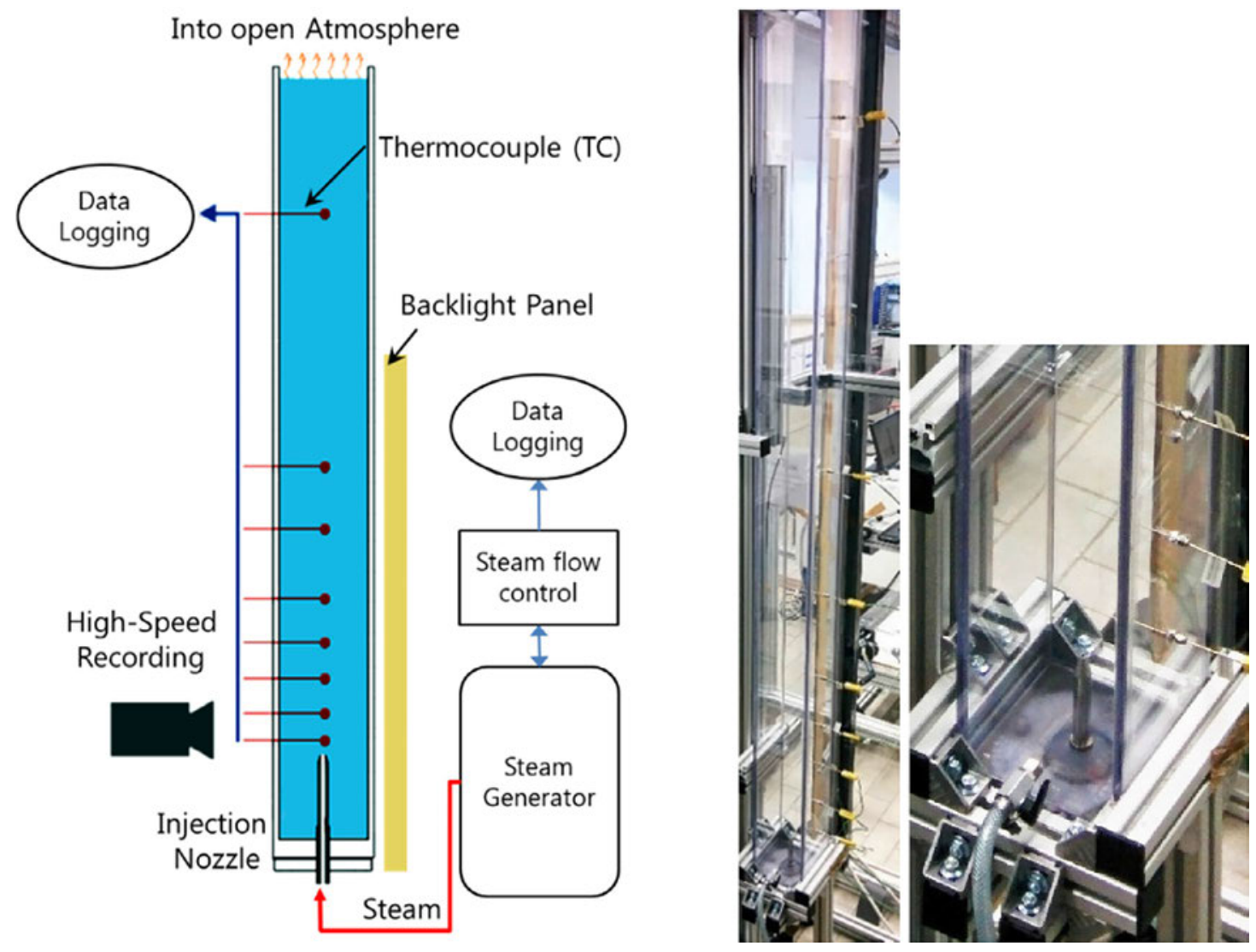

Fig. 1. Left: Experimental facility of the ADS simulator. Right: Real test section, thermocouples (TCs) appears to the right side and the steam injection nozzle at the bottom.

allows optical observation and a continuous operation with tempera tures up to $130^{\circ} \mathrm{C}$. The channel top is open and thus the excess of vapor is vented into the surrounding room atmosphere. The steam generator provides a maximum of $10 \mathrm{~kW}$, which also sets the maximum available steam mass flow rate. The distilled water used to generate the steam is degassed by boiling it for about $30 \mathrm{~min}$ before the beginning of ex periments. The steam leaves the steam generator and passes through a control valve, a cyclone moisture separator, and a vortex flow meter before it enters the steam injection nozzle. The cyclone separator en sures that only dry steam passes through the flow meter and thus a correct measurement of the mass flow rate can be achieved. A tem perature sensor is integrated into the vortex flow meter which allows measuring the temperature of the passing steam and the corresponding steam density (assuming steam in a saturated condition). Consequently, the mass flow rate can be obtained directly from the flowmeter. A Proportional Integral (PI) mass flow controller adjusts the opening of the control valve to keep the mass flow rate constant at the desired input value. Due to the low mass flow rate, only the average mass flow rate can be kept constant with a small deviation.

The steam is injected via an upward injection nozzle with a $4 \mathrm{~mm}$ diameter opening. The nozzle is installed at the center of the channel and the size of the opening was chosen so that it results in a steam output velocity close to the one occurring in realistic AP1000 ADS sparger holes (Fig. 2).

The tip of the nozzle is located approximately $0.095 \mathrm{~m}$ from the bottom of the test section, at a similar distance from the liquid surface as the ADS spargers. A set of eight K type TCs are installed into the test section to measure the axial temperature distribution evolution (Fig. 1). The TCs are built into a $1.5 \mathrm{~mm}$ stainless steel envelope, and they are inserted horizontally from the side so that the tip of each TC is located at the center of the test channel. The axial distribution of the sensors was chosen so that a finer axial resolution is obtained close to the injection nozzle as shown in Fig. 1. The distances of the TCs from the tip of the injection nozzle were: $0.05,0.15,0.275,0.4,0.55,0.8,1.15$ and $2 \mathrm{~m}$. The signals from the flowmeter and the TCs are recorded via ap propriate data acquisition units into the measuring PC. Both the steam mass flow rate and temperatures are logged each $1 \mathrm{~s}$ during experi ments. The accuracy of the K type TCs class 1 is $\pm 1.1 \mathrm{~K}$, however the extension cables from the TCs into the data acquisition unit adds an error of $\pm 0.8 \mathrm{~K}$ and thus the temperature measurements will have a measuring error of $\pm 1.9 \mathrm{~K}$. The accuracy of temperature measurement can be improved by calibrating the TCs. The steam mass flow rate is measured using a vortex flowmeter with a $\pm 2.55 \%$ accuracy.

In order to acquire the steam distribution at different stages, an Imager Pro $4 \mathrm{M}$ high speed camera was implemented. A white black light LED panel was used to illuminate the test section providing a homogeneous illumination from the surface of the panel. The bottom side of the panel was placed at the lower end of the test section which allowed the observation of about $0.9 \mathrm{~m}$ of the channel from the bottom (up to the sixth thermocouple). Image processing programs developed by the TUM researchers (Al Issa et al., 2014) allow eliminating the background from the raw images, filling white reflections inside bub bles, and removing remaining noise including tiny air bubbles if desired (Fig. 3a c). The result of this procedure is a clean image that includes existing steam or steam bubbles with a white background for water (Fig. 3d).

The intensity of a processed image at a specific frame is defined as a function of the specific location $(x, y)$, then a probability function $\Psi(x, y)$ which could be two different values $(0,1)$ is defined depending on whether the intensity is equal to zero or not, respectively. The time averaged probability at each pixel will represent the $2 \mathrm{D}$ projected time averaged void fraction as $\alpha(x, y)=\sum_{0}^{N_{\max }} \frac{\Psi_{\mathrm{t}}(x, y)}{N_{\max }}$. Where $N_{\max }$ is the total number of averaged instances (3000 in the current work). If the effect of superposition becomes low or negligible, such distribution can be 


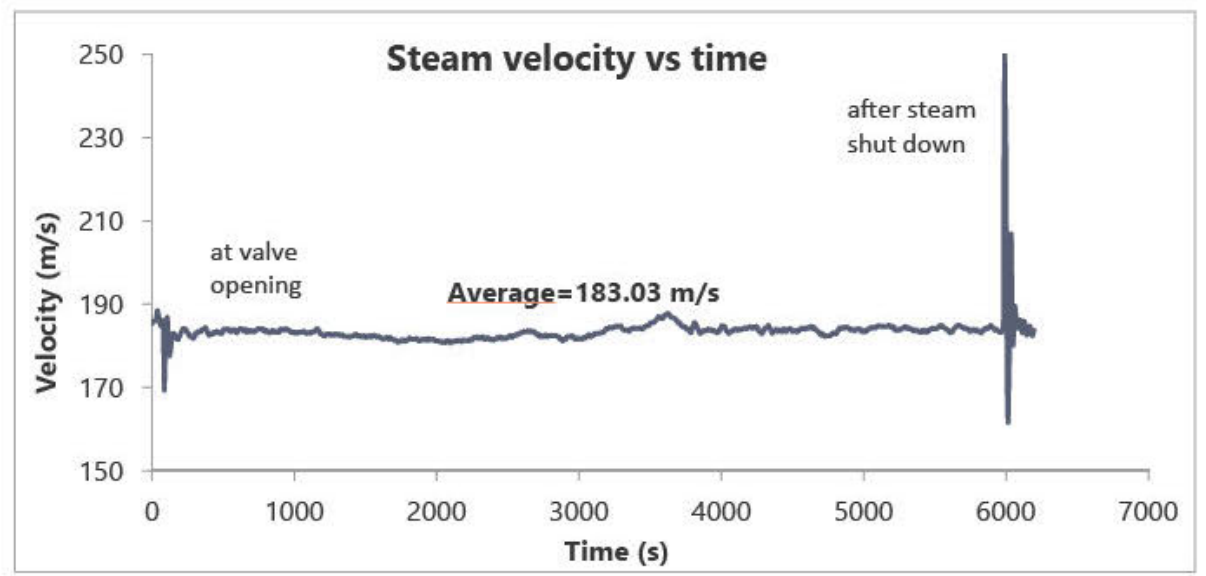

Fig. 2. Injected steam velocity during the experiment (one second averaged filtering is performed).

considered as a good approximation of the time averaged void fraction within the mid plane of the channel. This is valid in current experi ments when the water temperature is below the saturation temperature and steam bubbles are detaching one after the other. The over men tioned time averaged distribution can still be used as a qualitative evaluation of the time averaged void fraction distribution when the superposition effect becomes significant.

Experimental observations of steam injection into the channel noted three stages of steam condensation in accordance with the water tem perature increase:

- Stage 1: Water temperature remains highly subcooled below $60^{\circ} \mathrm{C}$. Steam is fully condensed at nozzle; no steam plume is visible at the nozzle tip.

- Stage 2: The liquid is still subcooled, but towards the end of this stage the water temperature starts to approach saturation especially at the lowest thermocouple. A steam plume is visible at the nozzle tip; steam bubbles detach off the plume and condense while rising in subcooled liquid.

- Stage 3: The water temperature starts to approach the corresponding saturation temperature at each hydrostatic elevation. Steam bubbles rise and can reach the top of the channel, the channel condensation efficiency is reduced and eventually, flashing occurs.

For stages $2+3$, steam fraction distributions were recorded for $2 \mathrm{~s}$ at different instances and a time averaged steam fraction distribution was calculated as explained previously in Fig. 3 . Table 1 illustrates the 14 samplings performed during the test and the corresponding time/ measured temperature at each TC.
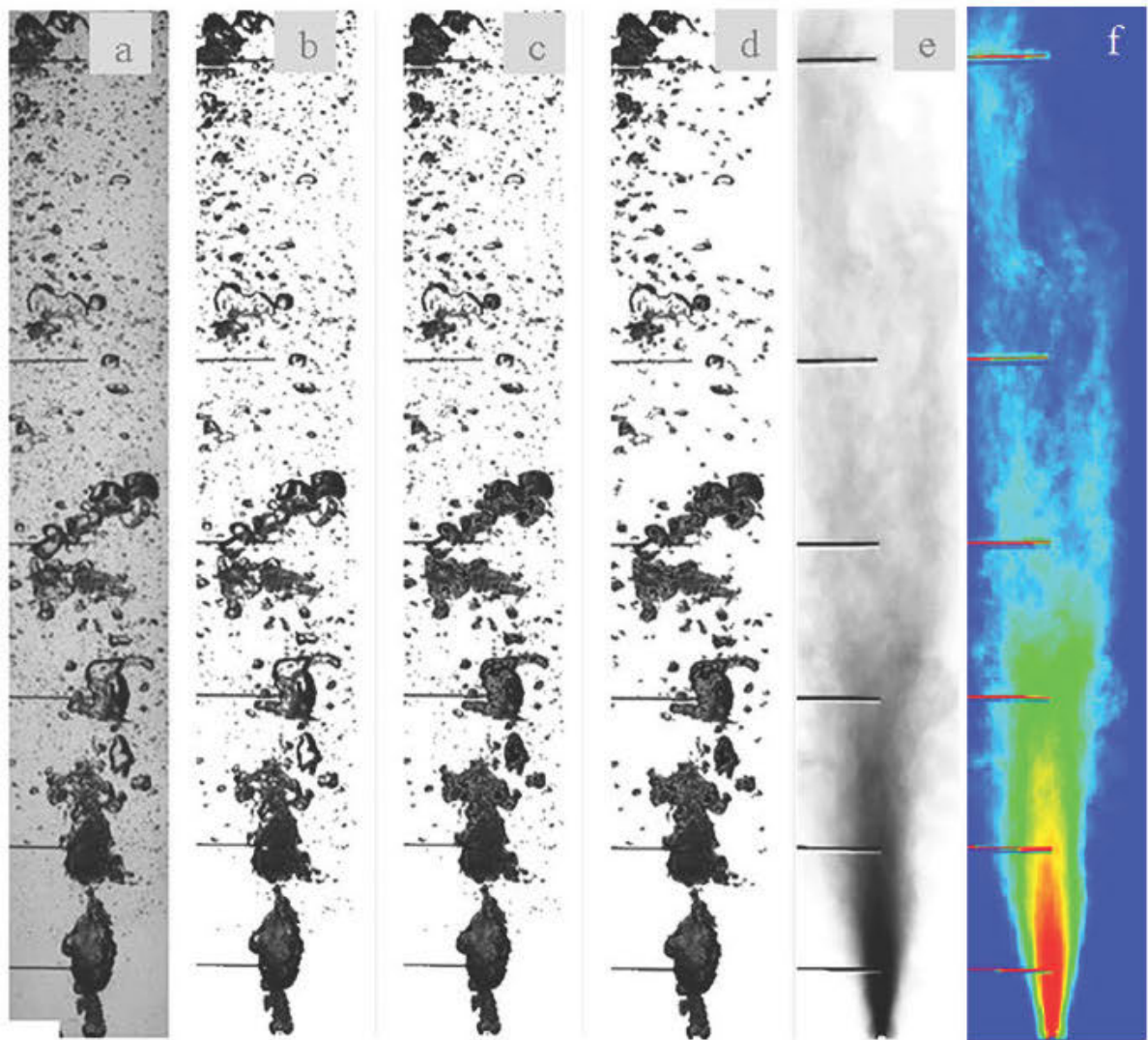

Fig. 3. Illustration of the performed image processing: a: Raw image, b: Removing the background, c: Filling of white reflections, d: Removing tiny air bubbles, e: $2 \mathrm{~s}$ time-average, f: color scale of the timeaverage in e. (For interpretation of the references to color in this figure legend, the reader is referred to the web version of this article.) 
Table 1

Temperature distribution during recorded cases, saturation temperature is shown in last column.

\begin{tabular}{|c|c|c|c|c|c|c|c|c|c|c|c|c|c|c|c|}
\hline \multicolumn{16}{|c|}{ Measurement times } \\
\hline & 1 & 2 & 3 & 4 & 5 & 6 & 7 & 8 & 9 & 10 & 11 & 12 & 13 & 14 & $T_{s}\left[{ }^{\circ} \mathrm{C}\right]$ \\
\hline$t[s]$ & 150 & 525 & 1020 & 1690 & 2435 & 3720 & 4145 & 4900 & 5058 & 5285 & 5425 & 5545 & 5760 & 5872 & \\
\hline TC1 & 31.0 & 39.2 & 47.7 & 56.8 & 66.9 & 83.5 & 89.1 & 99.6 & 101.8 & 103.1 & 103.7 & 103.6 & 103.8 & 104.0 & 104.0 \\
\hline $\mathrm{TC} 2$ & 28.7 & 37.0 & 45.7 & 55.0 & 66.2 & 82.5 & 87.6 & 95.9 & 97.7 & 99.7 & 101.6 & 101.6 & 102.6 & 103.0 & 103.7 \\
\hline TC3 & 28.0 & 36.4 & 44.8 & 54.2 & 65.3 & 82.1 & 86.9 & 95.2 & 97.1 & 99.3 & 101.1 & 101.4 & 102.1 & 102.6 & 103.4 \\
\hline TC4 & 27.3 & 35.7 & 43.6 & 54.0 & 64.6 & 81.7 & 86.4 & 94.7 & 95.9 & 98.2 & 100.2 & 101.0 & 102.0 & 102.4 & 103.1 \\
\hline TC5 & 26.4 & 35.7 & 42.6 & 51.9 & 62.5 & 78.4 & 85.0 & 93.4 & 95.3 & 98.2 & 99.5 & 99.5 & 101.6 & 101.6 & 102.7 \\
\hline TC6 & 25.9 & 31.6 & 42.1 & 50.3 & 62.3 & 78.6 & 82.8 & 92.8 & 94.8 & 95.1 & 96.6 & 98.6 & 101.3 & 101.5 & 102.1 \\
\hline TC7 & 25.5 & 29.8 & 37.4 & 49.3 & 58.3 & 75.5 & 81.3 & 90.1 & 91.7 & 94.7 & 96.7 & 96.6 & 99.4 & 100.2 & 101.3 \\
\hline TC8 & 25.7 & 28.1 & 34.8 & 45.6 & 56.2 & 73.2 & 78.6 & 87.2 & 88.9 & 90.7 & 92.5 & 93.5 & 96.2 & 97.8. & 99.2 \\
\hline
\end{tabular}

\section{GOTHIC model}

\subsection{Geometry and mesh}

This section describes the GOTHIC model as applied for the re ference case. The reference case parameters (mesh size, boundary conditions, and physical models) were chosen according to the GOTHIC best practices (EPRI, 2014).

The geometry data were taken from the experimental facility. Fig. 4 shows the geometry and the mesh adopted for the reference case. Two Control Volumes (CV) were created; the first one represents the test channel (CV1) and the second one represents the atmosphere of the laboratory room (CV2). Both CVs are connected hydraulically with a $3 \mathrm{D}$ connector. The test channel CV has a $15 \times 15 \mathrm{~cm}$ cross section with a $2.5 \mathrm{~m}$ height and it is initially filled with water up to $2.254 \mathrm{~m}$ from the bottom of the channel. The laboratory room $\mathrm{CV}$ is considered as a cube of $10 \mathrm{~m}$ edge length $\left(1000 \mathrm{~m}^{3}\right.$ volume, see Fig. $4 \mathrm{a}$ where the dashed line represents the laboratory $\mathrm{CV}$ ). Lower rectangle represents the jet flow BC. Upper rectangle and left rectangle represent pressure BCs. The in jection nozzle is modeled with a cylinder blockage of $0.004 \mathrm{~m}$ diameter and $0.095 \mathrm{~m}$ height (Fig. 4b, upper image represents $\mathrm{X}$ axis nodes. Bottom image represents $\mathrm{Z}$ axis and $\mathrm{X}$ axis nodes close to the injection nozzle). The TCs were not modeled as it was experimentally noticed that they did not cause a considerable distortion of the main flow be cause of their small size $(1.5 \mathrm{~mm})$ of diameter.

A 2D hexahedral mesh was created consisting of 400 cells. The cells are distributed in 57 axial levels along the $\mathrm{Z}$ axis and 7 divisions along the $\mathrm{X}$ axis (Fig. 4b). The position of the TCs agree with the position of certain cells and thus an accurate comparison can be made with ex perimentally measured temperatures. The hydraulic diameter of the cell where steam is injected was set to $4 \mathrm{~mm}$, so the cell Re number could be similar to the obtained in the experimental test, as it is recommended in (Andreani et al., 2015) for PANDA simulations. The rest of the channel volume was meshed using a maximum mesh expansion ratio of 1.5

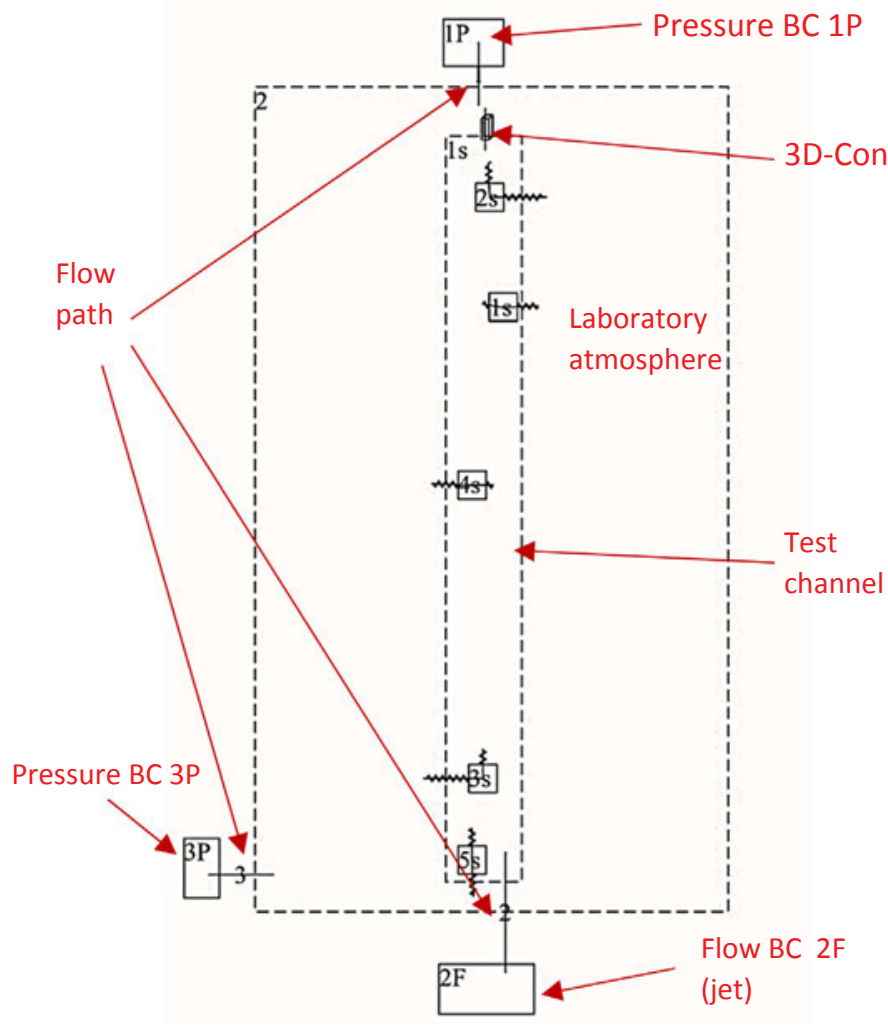

(a)

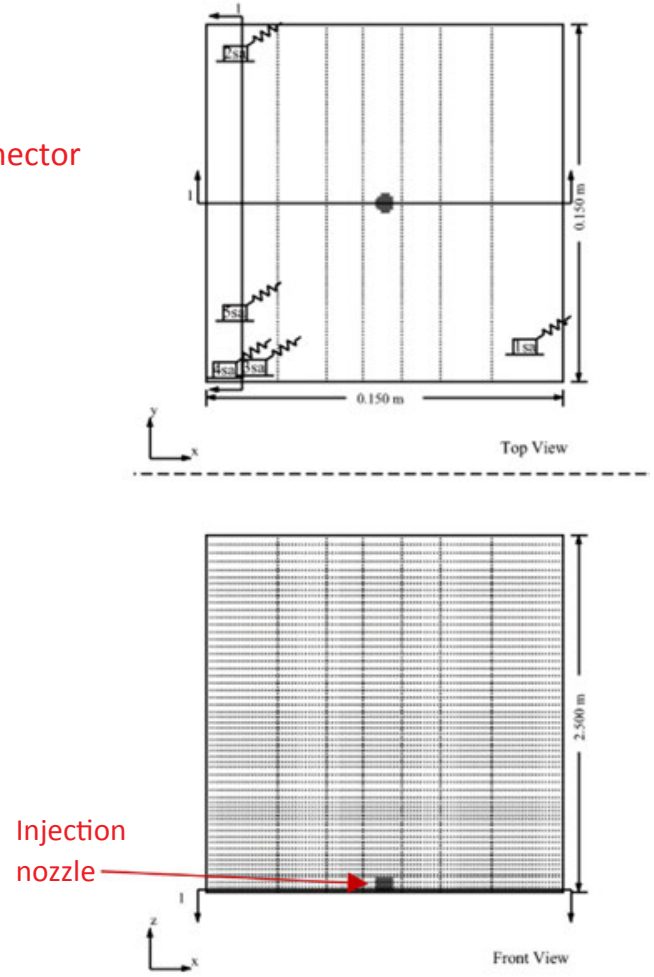

(b)

Fig. 4. Geometry scheme and meshing (reference case). (a) Geometry scheme. (b) Meshing. 
which resulted in cells with a size between 0.01 and $0.06 \mathrm{~m}$ in the $\mathrm{Z}$ axis, and 1.45 in the $X$ axis, where the cells sizes vary between 0.0163 and $0.03 \mathrm{~m}$. The aspect ratio varies from 0.23 to 1.69 .

The selected space discretization of the advection term was the Bounded Second Order and Upwind (BSOUP) method. This method is implemented in GOTHIC and has been adapted from (Papadakis and Bergeles, 1995); it reduces the numerical diffusion with a penalty of computational time. A first order upwind method is also available in GOTHIC, besides modified methods with flux limiters. These methods are discussed in Section 4.2.2.

A 3D model was created to be compared with the $2 \mathrm{D}$ one, main taining the same mesh in the $\mathrm{X}$ and $\mathrm{Z}$ axis, adding a $\mathrm{Y}$ axis with the same discretization as the $\mathrm{X}$ axis. After performing different simulations comparing 2D 3D models it was noticed that with the 3D one, the mixing effect was higher than in the 2D model, achieving a lower thermal distribution and it was concluded that a finer 3D mesh was needed to capture the phenomena for this experiment. Nevertheless, increasing the number of cells implies unaffordable computational cost for conducting a proper sensitivity study for the main parameters of the simulation, therefore it was decided to use a $2 \mathrm{D}$ model for these si mulations. In future works, the 3D model will be developed taken into account the lessons learned from the 2D model.

\subsection{Boundary conditions $(B C)$}

The steam injection was considered via the mass flow Boundary Condition BC $2 \mathrm{~F}$ (see Fig. 4a) equal to the mass flow rate in the ex periment presented as velocity in Fig. 2. The pressure at the $\mathrm{BC}$ was set to the hydrostatic pressure of the column of the water at the tip of the nozzle $(117.117 \mathrm{kPa})$ and the temperature to the corresponding sa turation temperature $\left(104.2^{\circ} \mathrm{C}\right)$.

The laboratory room (CV2) was kept at $96 \mathrm{kPa}$ and $24.5^{\circ} \mathrm{C}$ with BC $1 \mathrm{P}$, see Fig. 4a. To maintain nearly constant temperature $\left(25.4^{\circ} \mathrm{C}\right)$ and humidity (43\%) in the laboratory room CV, BC 3P is used with a pressure value equal to the atmospheric pressure at this elevation stablishing as a reference the pressure on the top of the channel $(96.0275 \mathrm{kPa})$, see Fig. 4a. This BC provide a natural circulation path which prevents the increase of temperature or the changes in humidity inside the laboratory room CV because of the steam released from the channel.

\subsection{Initial conditions}

Initial conditions for the simulation were taken from the experi mental data. An initial temperature of $25.4{ }^{\circ} \mathrm{C}$ was assigned to the channel's water and air, and laboratory room including the connected pressure BCs. As related previously, the initial water level was set to $2.254 \mathrm{~m}$.

The initial velocity of both phases is pre established as zero in all the computational cells. The turbulent sources, turbulent kinetic energy and turbulent dissipation rate are also set to zero. The channel walls have non slip condition.

\subsection{Physical models}

A multiphase Eulerian Eulerian modeling is applied. It solves the conservation equations for mass, momentum and energy for multi component, multi phase flow for three fields: steam/gas mixture, con tinuous liquid and liquid droplets fields. For these fields, GOTHIC cal culates the relative velocities between the separate but interacting fluid fields, including the effects of two phase slip on pressure drop. The heat transfer between phases and contact surfaces is also calculated.

The heat transfer from the vapor to the steam/water interphase and from the liquid to the interphase is calculated considering the inter phase temperature, the convective heat transfer coefficients (HTCs) on the vapor (v) and liquid (1) sides of the interphase, Eqs. (1) and (2), and the interphase area. The phase change rate depends on the mass transfer coefficient (obtained from the mass transfer $\mathrm{Nu}$ number, Eq. (3)), the molecular weight of steam and the steam mole fraction at the interphase and the bulk vapor.

$N u_{l l}\left(d_{b}\right)=2+0.74 R e_{b l}^{1 / 2} \operatorname{Pr}_{1}^{1 / 3}$

$N u_{v l}\left(d_{b}\right)=2+0.74 R e_{b v}^{1 / 2} \operatorname{Pr}_{\mathrm{v}}^{1 / 3}$

$N u_{m l}\left(d_{b}\right)=2+0.74 R e_{b v}^{1 / 2} \operatorname{Sc}_{\mathrm{v}}^{1 / 3}$

Where $d_{b}$ is the bubble diameter, $R e_{b l}, R e_{b v}$ are the bubble Reynolds number for liquid and vapor respectively; $P r_{l}, P r_{v}$ and $S c_{v}$ are the Prandl number for liquid, vapor and the Schmidt number for vapor (EPRI, 2014).

The heat transfer rate on the channel wall inner and outer sides will determine the heat loss from the channel fluid into the surrounding atmosphere at different elevations, and thus it will affect almost all observed phenomena temperature distribution and steam condensation (steam fraction and flashing time).

In the reference case, heat transfer through the channel walls is modeled with thermal conductors (THC). Available correlations for conductor heat transfer are forced convection, natural convection and radiation. The model has five THC, which represent the channel walls and floor internal side connected to the external side of the walls in contact with the laboratory volume. In this case, an external HTC was applied to the inner side of the channel with natural convection option activated. Wall condensation was handled using Diffusion Layer Model with Film roughening and Mist formation (DLM FM). The diffusion layer model calculates the condensation rate and sensible heat transfer rate using heat/mass transfer analogies and in this case the model considers the film roughening, the heat transfer between the wall and film and mist generation in the boundary layer. On the outer side of the channel a constant HTC of $4.51 \mathrm{~W} / \mathrm{m}^{2} \mathrm{~K}$ was applied and it was de termined using a vertical plate correlation for natural convection (Incropera et al., 2011) using the experimental data measurements. Table 2 shows the applied values of physical properties, which corre sponds to the material of the channel wall in the experiment, made of polycarbonate. After different own studies on thermal conduction in the nozzle, it has been seen that the effect of modeling it with a THC is almost negligible in this case as the inside of the nozzle is in thermal balance with the external side. For that reason, the nozzle was not modeled as a thermal structure.

Turbulence was modeled via the $\mathrm{k} \varepsilon$ STD model (standard two equation $\mathrm{k}-\varepsilon$ turbulence model) in both phases steam/water in dependently with the molecular diffusion enabled. The molecular dif fusion is used as an extra term in the diffusion in the governing equa tions.

No turbulent sources were considered in the calculation domain. The Prandtl and Schmidt turbulent numbers in the liquid and the vapor phase are set to 1 as recommended in GOTHIC User's Manual (EPRI, 2014).

\section{Simulation results}

In this section, the results obtained from the simulations are pre sented. In the first subsection, the results corresponding to the reference case are shown and analyzed. Then, several sensitivity cases are pre sented and compared with experimental results.

Table 2

Thermal properties of polycarbonate (Incropera et al., 2011).

\begin{tabular}{llll}
\hline $\mathrm{T}\left[^{\circ} \mathrm{C}\right]$ & $\rho_{\mathrm{cn}}\left[\mathrm{kg} / \mathrm{m}^{3}\right]$ & $\mathrm{k}_{\mathrm{cn}}[\mathrm{W} / \mathrm{m} \cdot \mathrm{K}]$ & $\mathrm{C}_{\mathrm{P}, \mathrm{cn}}[\mathrm{kJ} / \mathrm{kg} \cdot \mathrm{K}]$ \\
\hline 30 & 1200 & 0.21 & 1.26 \\
\hline
\end{tabular}



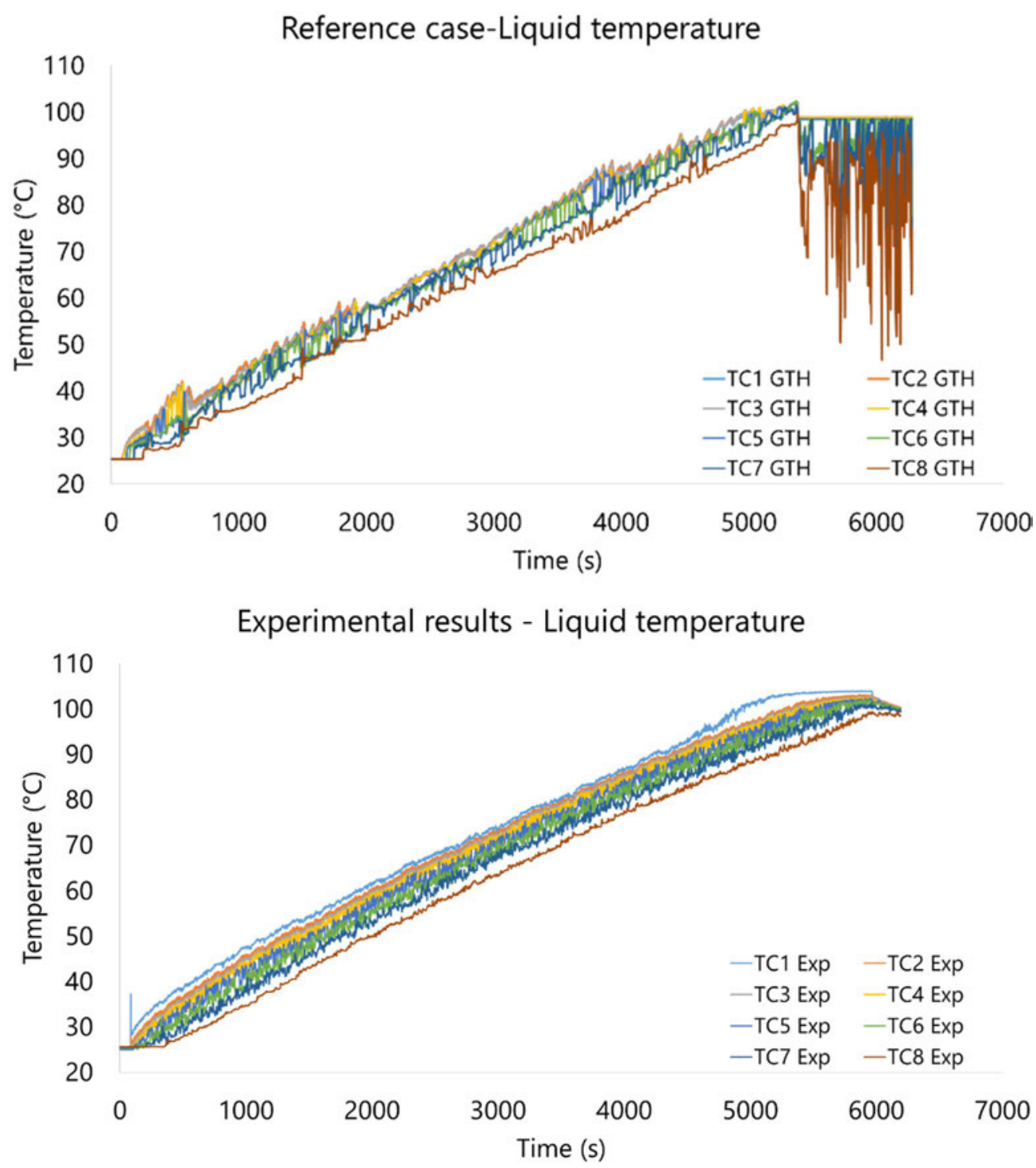

Fig. 5. Top: Temperature at every TCs, Bottom: Experimental results.

\subsection{Results of the reference case}

In this subsection, the results from the reference case are presented. The reference case was set up considering the best practice from the GOTHIC developers and the user's community.

\subsubsection{Temperature profiles}

As shown in Fig. 5, the time development of all TCs in GOTHIC simulation and experimental data of the reference case is represented. The fluctuations at 200, 1600 and $3800 \mathrm{~s}$ are result of some fluctuations in the flow input imposed. A gradual and almost linear increase of the temperature is observed in the experiment and simulation. Near $\mathrm{t}=5450 \mathrm{~s}$ the lower sections of the channel start to reach the saturation temperature, however due to the fact that the development of the steam fraction is quite different at final stages as Section 4.1.2 will show, TC1 simulation results do not come into a direct and permanent contact with steam as in the experimental test, and thus the way the temperatures reach the saturation is different between simulation and experiment. Flashing occurs at $5458 \mathrm{~s}$ in simulation, this time is about $500 \mathrm{~s}$ earlier than in experiment. In the following sections the reasons of this dif ference will be explained.

Fig. 6 shows the temperature development comparison between experimental test and simulation of the reference case for each TC separately. In general, there is a good agreement with the experimental data, except for TC1 when saturation temperature is approached, and TC8 which is heavily affected by occurrence of flashing. The decrease of temperature in TC6, TC7, and TC8 at the end of the transient is due to the loss of water/hydrostatic pressure after flashing.

In order to compare the vertical temperature distribution between simulation and experiment, the temperature axial profiles were plotted from GOTHIC results against experimental data. Fig. 7 shows this comparison in the first and second stages (see Table 1). In general, there is a good agreement until the end of stage 2, where a clear deviation between GOTHIC and experimental results start to appear. The reason for these differences can be due to several reasons:

- Distribution and development of the velocity field and accom panying heat transport can be different between experiment and simulation. However, this reason cannot be verified as no velocity measurements were conducted in the experiment.

- The heat loss from the channel wall was homogeneously imposed in the boundary condition, which may not be the case in the experi ment.

- The heat/mass transfer between steam and water, which is handled internally in GOTHIC and cannot be modified by the user. 


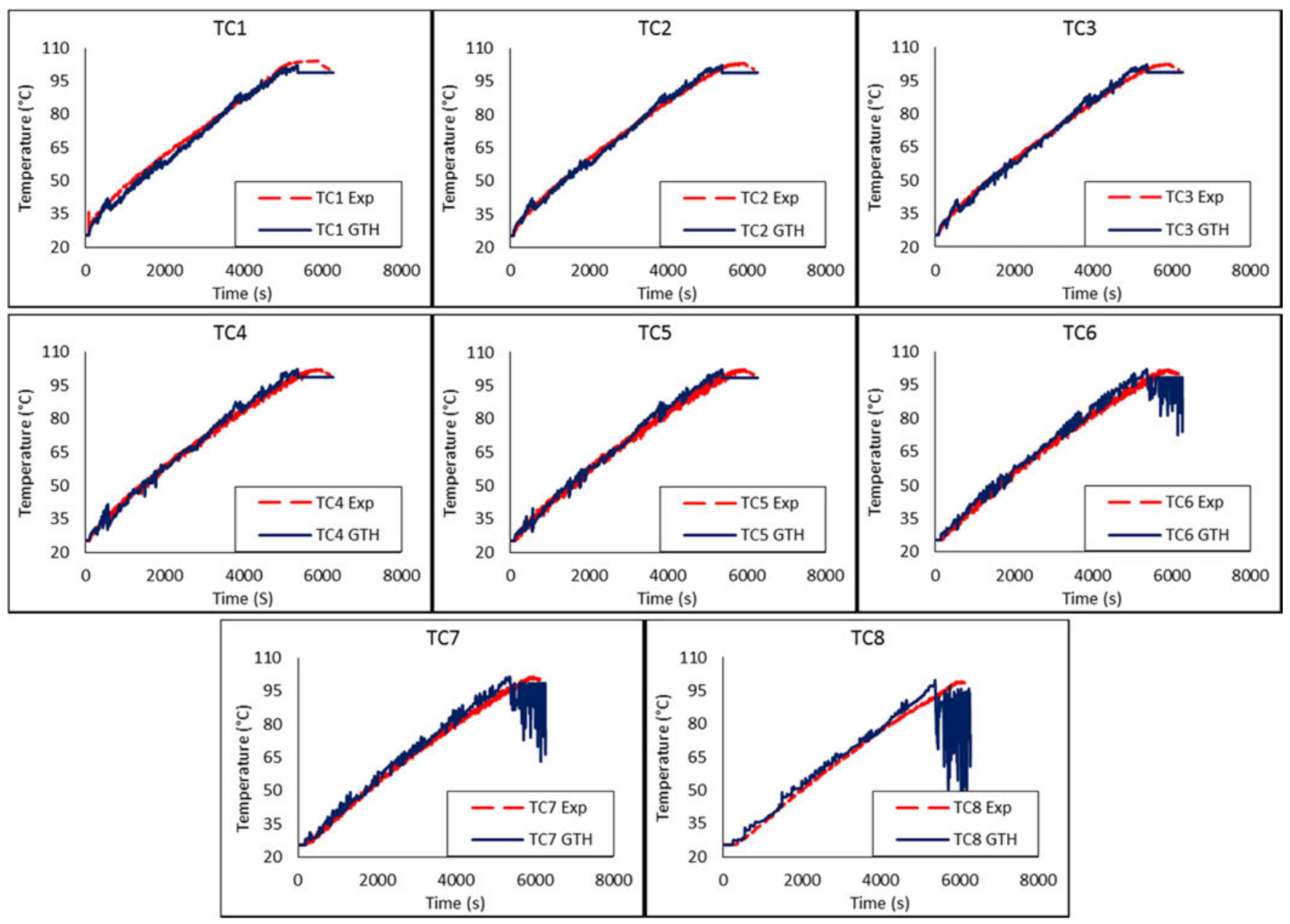

Fig. 6. GOTHIC simulations of the reference case versus experimental results for each of the 8 TCs.

Fig. 8 shows the comparison for stage 3. Results here disagree due to the earlier occurrence of flashing in simulations and the loss of water from upper elevations (beyond $1.2 \mathrm{~m}$ ).

\subsubsection{Steam fraction distributions}

In order to obtain 2D steam fraction distributions and compare it with extracted experimental results, GOTHIC results were processed with ParaView software (Ayachit, 2015). 2D plots of the steam fraction were produced at different time steps corresponding to the 14 sam plings (Table 1). It should be noted again that the experimentally ob tained distributions correspond to a time averaged 2D side projected distributions and the comparison is only qualitative. Fig. 9 shows the 2D steam fraction distributions obtained from GOTHIC simulations of the reference case for the first 4 measuring times, 14 . For these cases, no steam plume was observed in the experiments and thus, only the simulation results are shown. In GOTHIC simulations, there was a visible steam plume that emerges from the nozzle despite the existence of high subcooled water. This fact is caused as GOTHIC has always a certain fraction of steam in the injection cell, as the steam cannot condense inside the pipe, as it is modeled as a BC and its small size. Another reason that can affect the heat transfer rate is the existing water velocity that results from establishment of natural circulation,
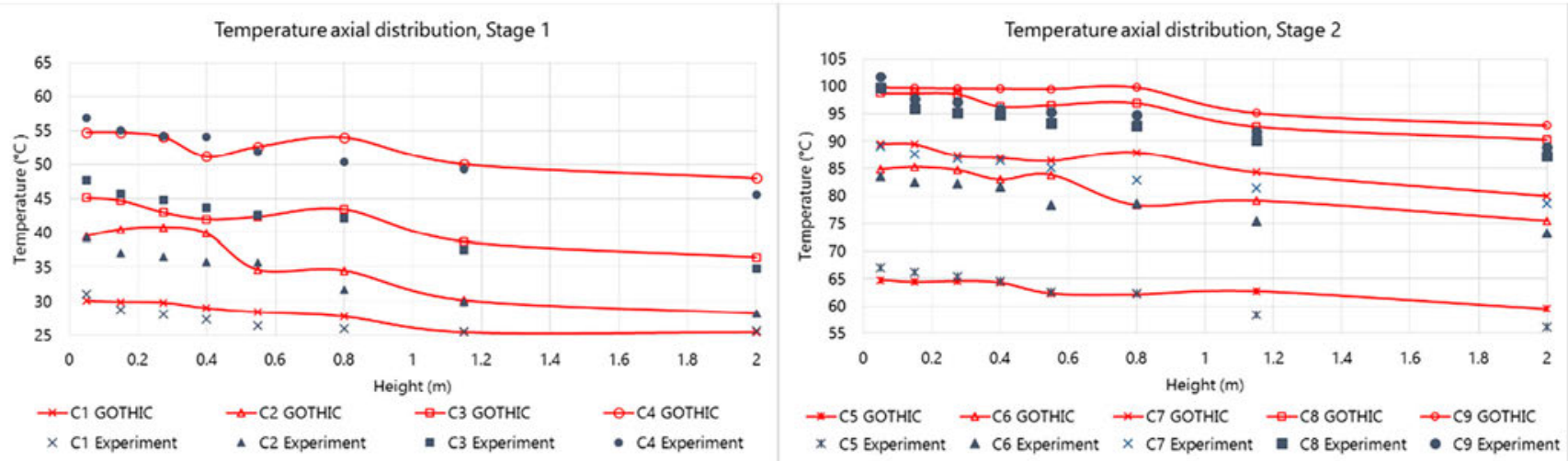

Fig. 7. Comparison of the axial temperature profiles between GOTHIC calculations and experimental data (reference case, average over 20 s): Stages $1 / 2$. 


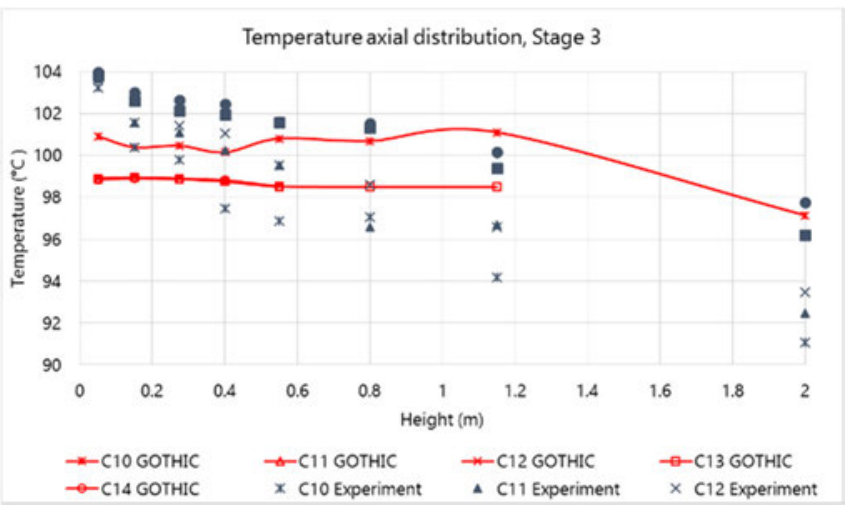

Fig. 8. Comparison of the axial temperature profiles between GOTHIC calculations and experimental data (reference case, average over 20 s): Stage 3.
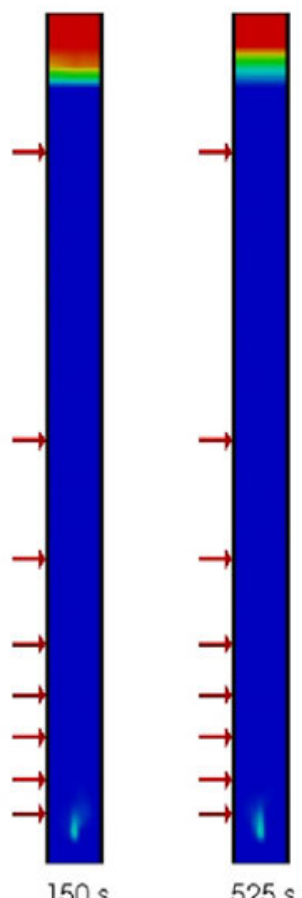

$525 s$

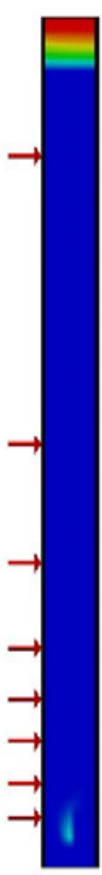

$1020 \mathrm{~s}$

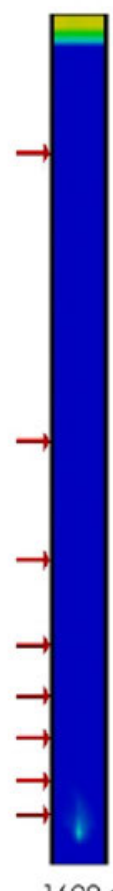

$1690 \mathrm{~s}$
Steam volume fraction

$\begin{array}{llllllllllll}0.0 & 0.1 & 0.2 & 0.3 & 0.4 & 0.5 & 0.6 & 0.7 & 0.8 & 0.9 & 1 .\end{array}$

Fig. 9. 2D Steam fraction distributions calculated for the reference case for measuring times 1-4. (Arrows indicates the position of TCs measurement in experiments).

however this parameter was not measured experimentally and thus simulation results cannot be validated. Future work will see PIV (Par ticle Image Velocimetry) measurement of the velocity field in water around the steam plume.

Fig. 10 shows a comparison between GOTHIC calculations and ex perimental data for stage 2 (measuring times 5 9). During this stage, the plume size in simulations is similar to the experimental data and it grows as water temperature increases as in the experiments. However, distributions (shape, extension, steam fraction gradient within the plume) are different from experiment ones. This is due to how GOTHIC solves the steam condensation plume surface in the simulations (ex plained previously in Section 3.4). It is close related to the spatial dis cretization, and as the mesh near the injection is relatively coarse the plume distribution is slightly different to the one obtained from the experiment. Besides, the experimental 2D images are a projection of a 3D geometry, so it must be advised that the comparison is not fully plausible. Fig. 11 shows the comparison results for stage 3 (Cases 10 14). Plumes out of simulations continue to grow in size in cases 1011 (at 5285 s, 5425 s respectively). However, starting from Case 11 (5425 s) distributions become very different due to early flashing in simulations; this is, the water suffers an instant evaporation and a considerable amount of inventory in the upper part is lost.

\subsection{Sensitivity analysis}

To analyze the influence of different model parameters and de termine the optimal ones for the reference case a sensitivity analysis was done in which the effect of: the mesh size, discretization scheme, turbulence model and heat transfer options for the channel wall, was evaluated upon the resulting accuracy in comparison with the experi mental data.

\subsubsection{Mesh sensitivity}

To examine the sensitivity of the solution to the applied mesh size and pick up a mesh size that is small enough to produce a plausible agreement with experiments, and large enough that the overall re sulting calculations nodes remain under maximum limit of GOTHIC meshes with different sizes were created. The following meshes were adopted in the $\mathrm{Z}$ direction:

- Za: 19 grid lines, with a maximum Aspect ratio: 1.3, mesh size be tween 0.09 and $0.2 \mathrm{~m}$.

- Zb: 26 grid lines, with a maximum Aspect ratio: 1.5, mesh size be tween 0.04 and $0.1 \mathrm{~m}$.

- Zc: 57 grid lines, with a maximum Aspect ratio: 1.5, mesh size be tween 0.01 and $0.064 \mathrm{~m}$.

- Zd: 94 grid lines, with a maximum Aspect ratio: 1.1, mesh size be tween 0.017 and $0.032 \mathrm{~m}$.

In the $\mathrm{X}$ direction the following meshes were adopted:

- Xa: 5 grid lines. Fixed mesh size: $0.03 \mathrm{~m}$.

- Xb: 7 grid lines, with a maximum Aspect ratio: 1.2 mesh size be tween $0.015 \mathrm{~m}$ and $0.03 \mathrm{~m}$.

- Xc: 17 grid lines, with a maximum Aspect ratio: 1.03 mesh size between $0.008 \mathrm{~m}$ and $0.01 \mathrm{~m}$.

The combination of all possibilities of above meshing schemes in $\mathrm{X}$ and $\mathrm{Z}$ directions results in a total cells number between 95 and 1598. The reference case had 399 cells (Zc Xb). Fig. 12 shows the adopted meshes. The evaluation of the performance of each mesh scheme depends on the evaluation of the total temperature average relative error $\left(\bar{\epsilon}_{T}\right)$ defined by equation [4] and the result of the evaluation for all possible mesh combinations are shown in Fig. 13.

$\overline{\epsilon_{T}}=\frac{1}{8} \sum_{i=1}^{8} \frac{1}{t_{\max }} \sum_{t=t_{0}}^{t_{\max }}\left|\frac{T_{i, \exp }(t)-T_{i, \text { Simulation }}(t)}{T_{i, \text { experiment }}(t)}\right|$

Regarding the ability of the different meshes to predict observed phenomena, it was noticed that mesh configurations with $\mathrm{Za}$ and $\mathrm{Zb}$ meshing schemes were not able to predict vertical temperature dis tribution and there was almost a homogenous mixing in the entire test rig. It is supposed to be produced because of the diffusivity induced by the increase of truncation error generated by the big cell size and the large aspect ratio between adjacent cells. The results show that the total average relative error is larger than in the reference case, see Fig. 13. Zc Xa and Zc Xc configurations achieve stratification temperature gra dient, with a comparable error to the reference case. The steam volume fraction has similar distribution to the reference case in all Zc config urations and flashing occurs almost at the same time. The average 


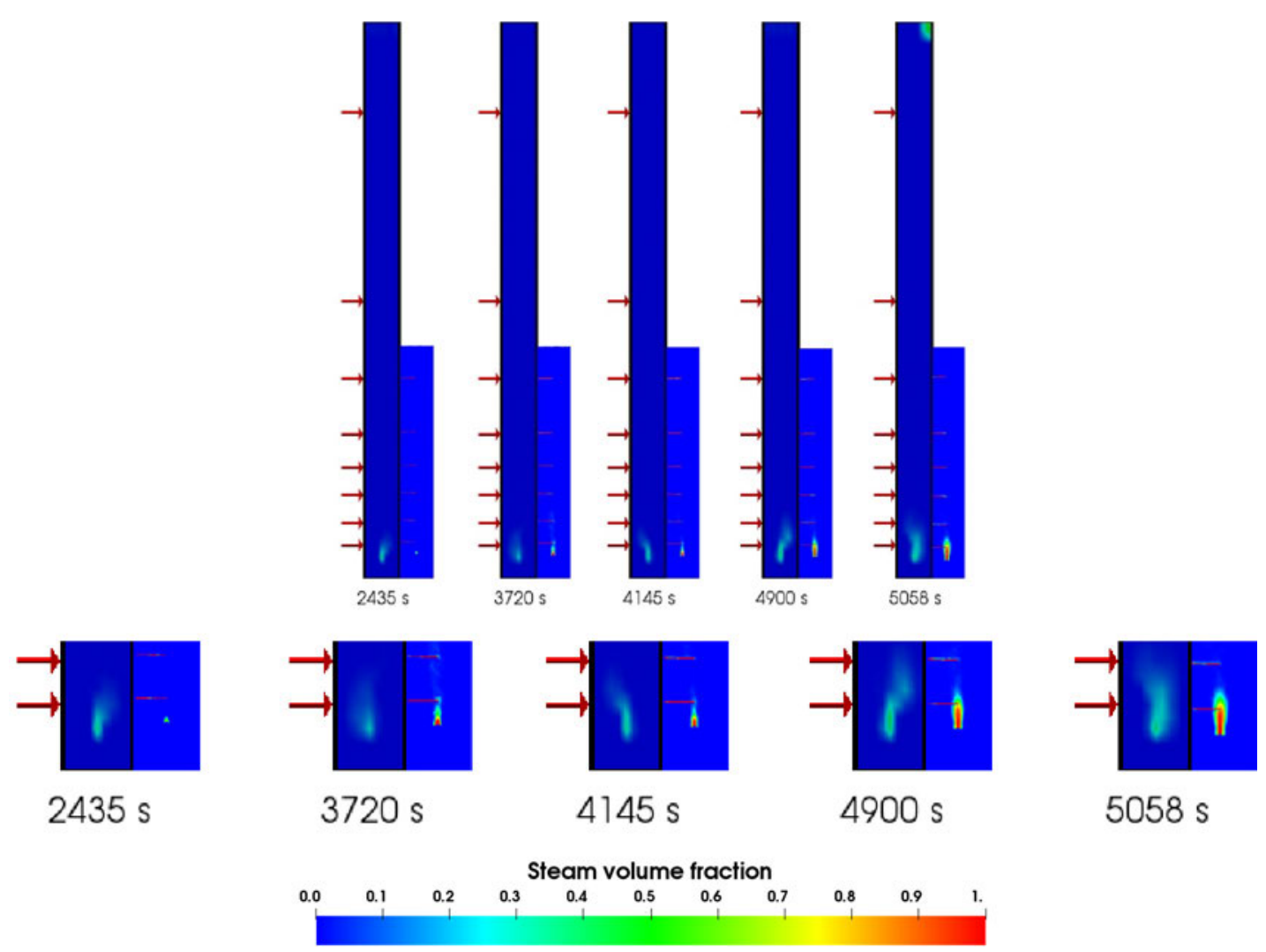

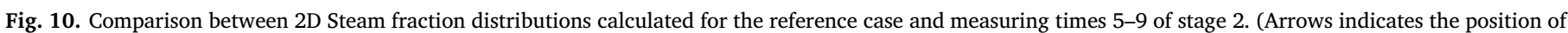
TCs measurement in experiments. Bottom insert shows detailed view close to injection nozzle).

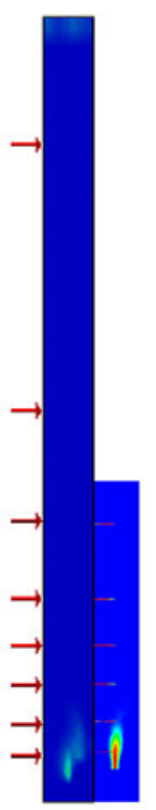

$5285 \mathrm{~s}$
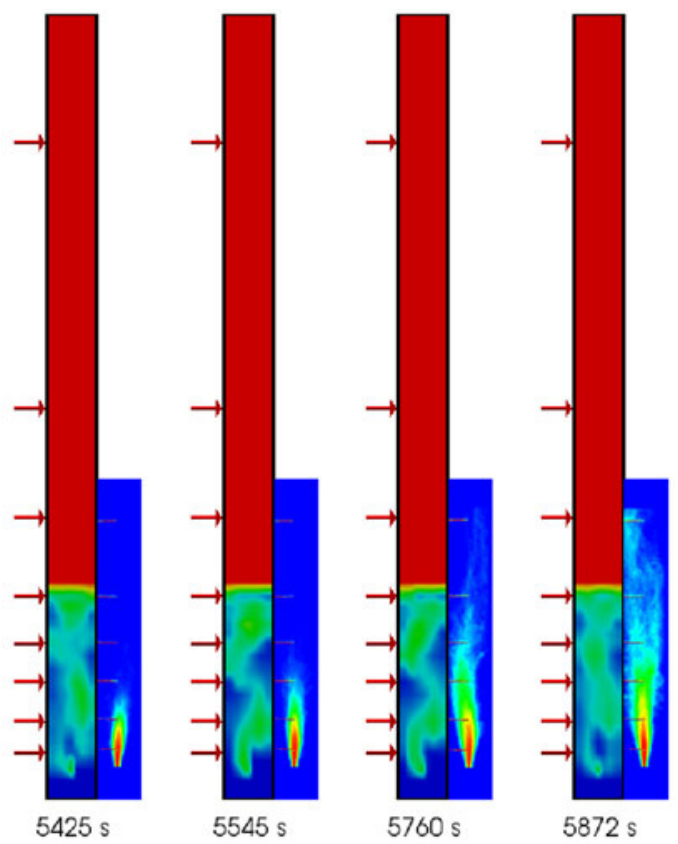

Steam volume fraction

0.0

0.1

0.2

0.3

Fig. 11. Comparison between 2D Steam fraction distributions calculated for the reference case and measuring times $10-14$ of stage 3 .

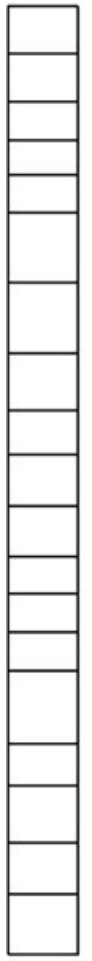

$\mathrm{Za}$

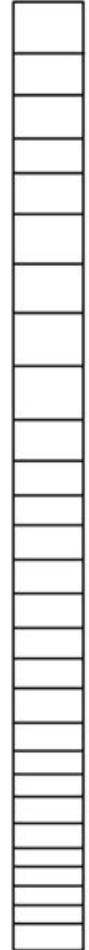

$\mathrm{Zb}$

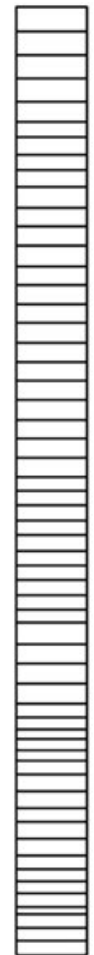

Zc

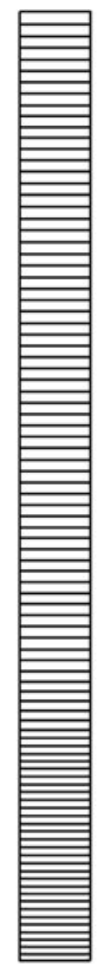

$\mathrm{Zd}$
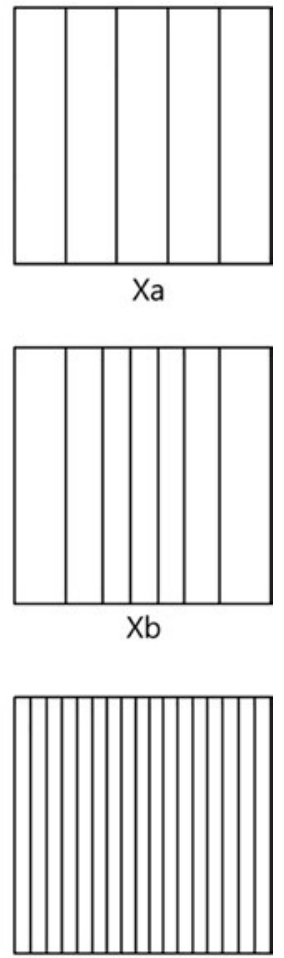

Xc

Fig. 12. Adopted meshes for the sensitivity study. 


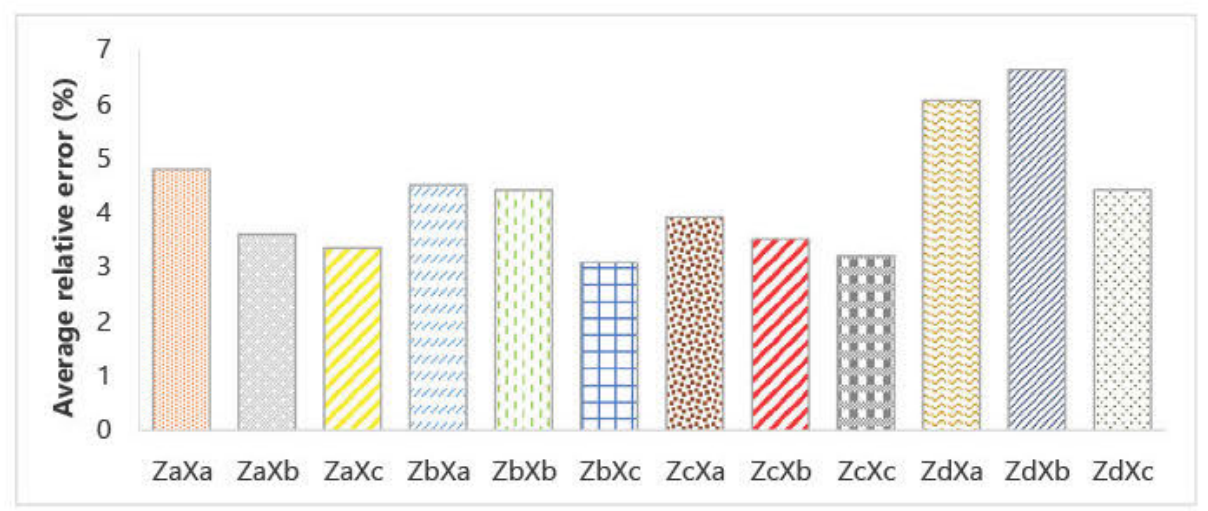

Fig. 13. Total average error for all mesh-combinations as defined in Eq. (4).

relative errors in $\mathrm{Zd} \mathrm{Xa}$ and $\mathrm{Zd} \mathrm{Xb}$ mesh configuration models are larger than the reference case due to mass and energy convergence problems. The energy error (relative to the initial system energy) in these simu lations is one order of magnitude larger than the reference case, being $4.5 \cdot 10^{-3} \%$ in $\mathrm{Zd}$ cases, and $10^{-4} \%$ in the reference case. The $\mathrm{Zd} \mathrm{Xc}$ model gives similar results to the reference case, and the time when flashing occurs is closer to the experiment. The steam fraction distribution is slightly better solved in this model because of the finer mesh. However, the time needed to simulate the full case is $55 \mathrm{~h}$ (compared to $2 \mathrm{~h}$ $30 \mathrm{~min}$ of the reference case), which limits its practical use in a larger model despite its better results.

\subsubsection{Discretization scheme}

The BSOUP method was applied as a discretization scheme in the reference case. However, three more schemes are available in GOTHIC: First Order UPwind (FOUP), Modified First Order UPwind, (MFOUP) and Flux Limiter Second Order Upwind (FLSOUP). The FOUP scheme uses the values upstream to evaluate the property on the boundaries of the cell and then use them to compute the value at the center of the cell taking into account the flow direction. This model is very stable but can overestimate the diffusion terms for fluids. The MFOUP and FLSOUP schemes apply a modified donoring scheme that is more suitable than FOUP or BSOUP for liquid injection (either continuous or droplets) into a gas filled sub divided volume when the liquid injection has significant momentum in more than one direction. Flux limiter schemes are in tended to reduce numeral diffusion due to strong gradients in convected quantities while preserving the stability of lower order advection schemes. MFOUP and FLSOUP schemes has been used to prove its ef fectiveness in other scenarios apart from the ones they were created for, if the important phenomena in the experiment could be simulated with them.

Similarly to the meshing sensitivity, the average total relative error for the temperature is calculated for each discretization scheme and each TC as follows:

$\overline{\epsilon_{T}}(i)=\frac{1}{t_{\max }} \sum_{t=t_{0}}^{t_{\max }}\left|\frac{T_{i, \text { exp }}(t)-T_{i, \text { Simulation }}(t)}{T_{i, \text { experiment }}(t)}\right|$

Results for calculated $\left.\bar{\epsilon}_{T}(i)\right|_{i=1-8}$ are shown in Fig. 14. Regarding the prediction of the observed phenomena according to the applied scheme, a temperature gradient was not achieved with FOUP and MFOUP schemes since these methods overestimate the diffusion terms for fluid and thermal stratification and thus it is difficult to reproduce using a coarse mesh, as the numerical error tend to generate a false mixing effect. The FLSOUP was able to achieve a slight temperature gradient; however, the average error is larger than in the reference case that uses the BSOUP scheme.

\subsubsection{Turbulence model}

GOTHIC can use two different models to calculate the turbulent terms: the Prandtl mixing length model and the selected two equation $\mathrm{k} \varepsilon$ model. The mixing length model (MIX L) provides reasonable re sults for situations involving uniform geometries and flow fields. The two equation model solves partial differential equations that model the transport of effective parameters for calculating local turbulence, ve locity scale and length scale. Variations on the $\mathrm{k} \varepsilon$ model are available in GOTHIC and have been studied in the sensitivity analysis:

- k $\varepsilon$ RG: $\mathrm{k} \varepsilon$ turbulence model with the Renormalized Group source term. This model include an advance source term developed by Yakhot (Yakhot and Orszag, 1986) in the dissipation transport equation in order to enhance capabilities to simulate mixing driven by highly buoyant discharges (Analytis, 2001a)

- $\mathrm{k} \varepsilon \mathrm{NL2}$ : $\mathrm{k} \varepsilon$ turbulence model with a second order approximation for the Reynolds stress term. In this model the Reynolds stress tensor is complemented by an additional quadratic nonlinear term (Analytis, 2001b) This model has been enhanced with the aim that that the anisotropic eddy viscosity relationship can allow the application of the $\mathrm{k} \varepsilon$ turbulence model to a wide range of three dimensional tur bulent flow (Craft et al., 1996; Speziale and Gatski, 1990).

The MIX L, k $\varepsilon$ RG, k $\varepsilon$ NL2 models and a model without turbulence modeling were applied adopting the mesh, discretization scheme, and the heat transfer used in the reference case. Regarding the reproduction of observed phenomena in experiments, clear temperature distribution was achieved in all cases. The flashing time is similar in all cases and flashing occurs between $600 \mathrm{~s}$ (k $\varepsilon$ NL2 case) and $300 \mathrm{~s}$ (k $\varepsilon$ RG case) earlier than the experiment. The steam fraction is similar to the re ference case in almost all the cases. In the model without turbulence modeling, the plume oscillation is not well predicted, creating differ ences in the steam fraction. Nevertheless, the steam distribution (size, shape of the plume) is similar to the reference case. In order to compare among different turbulence models, the temperature average error of each TC was calculated according to Eq. (5). Fig. 15 shows the results of this error for each turbulence model at each of the $8 \mathrm{TCs}$. In general, the $\mathrm{k} \varepsilon$ turbulence models provide better results than the MIX L model and the case without turbulence model.

\subsubsection{Heat transfer option on the channel wall}

In order to investigate the effect of the heat transfer rate on the obtained results six options were tested. The "Adiabatic" case does not consider the heat transfer on both sides. The "h GOTHIC" case is similar to the reference case, but the external wall HTC is calculated with natural circulation correlations implemented in GOTHIC (called Direct option in GOTHIC). The "Internal" case treats the conductors as a heat sink. The "FILM \#" cases modify the condensation treatment on the walls applying the different correlations for the condensation coeffi cients available in GOTHIC for this model: Uchida, Modified Uchida (Mouchida), Gido/Koestel (G K) and MAX (Maximum of Uchida and 


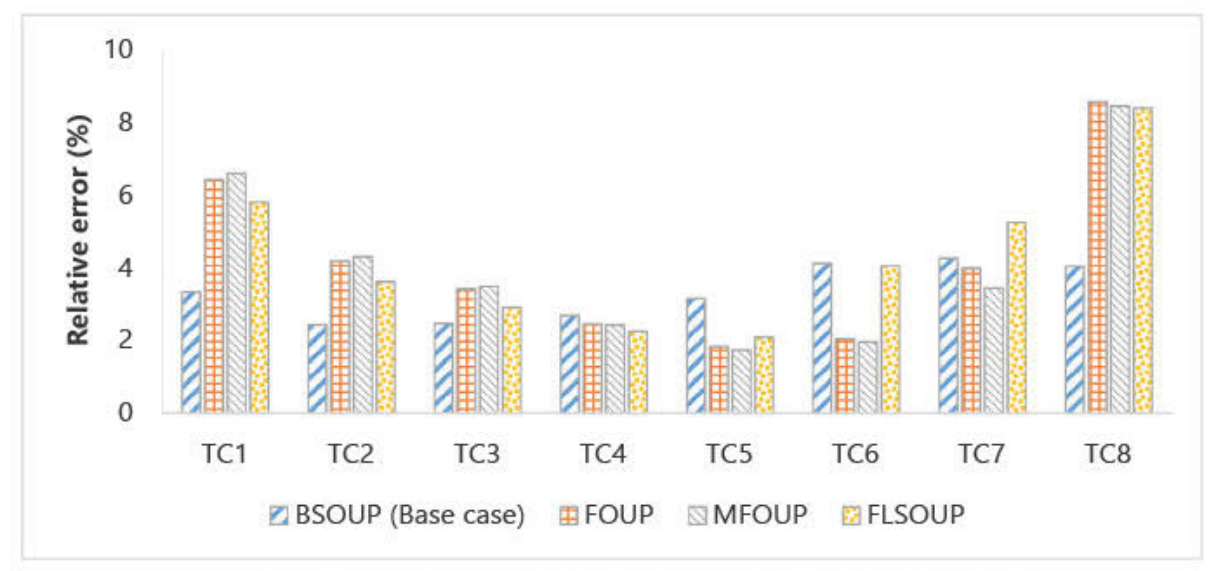

Fig. 14. Total average error for all discretization schemes as defined in Eq. (5).

Gido/Koestel). All above models were applied to the reference case using its mesh, discretization and turbulence modeling. Table 3 sum marizes the described configurations.

The change of the heat transfer model on the channel wall according to above mentioned options proved to have a small effect except for the adiabatic option upon results. Fig. 16 shows the total average relative error calculated for each TC according to Eq. (5). The large deviation that occurs in the adiabatic option comes from the earlier flashing (due to zero heat loss) compared to all other cases. It should be mention the insignificant difference observed when comparing the different corre lations for FILM option. However, the differences with the reference case, which uses the DLM FM model, are quite more appreciable, being the average relative errors scarcely higher than the reference ones in the lower middle TCs, and barely smaller in the upper TC (TC8).

\subsubsection{Simulation efficiency}

In order to compare combinations of all sub models and options shown earlier in previous sections, and to define an overall figure of merit; an indicator labelled as "Simulation efficiency $\eta$ " was proposed and it has been calculated for all presented cases as similar studies on sensitivity analysis; see (Fernández Cosials et al., 2016). This parameter takes into account the average temperature difference between TC1 and TC8 in the experiment $\left(\Delta T_{1-8}^{\text {exp }}\right)$ and in the simulation $\left(\Delta T_{1-8}^{\mathrm{sim}}\right)$, the total temperature average relative error $\left(E_{T}\right.$, see Eq. (5)), the difference between flashing time in the simulation $\left(t_{s_{\text {exp }}}\right)$ and the experiment $\left(t_{s}^{\text {sim }}\right)$, and the CPU computational time $\left(t_{\text {sim }}\right)$ as follows:

$\eta=\frac{10^{9}}{\left|\Delta T_{1-8}^{\exp }-\Delta T_{1-8}^{\text {sim }}\right|^{2} \cdot\left|t_{s}^{\text {exp }}-t_{s}^{\text {sim }}\right| \cdot \overline{\epsilon_{T}} \cdot t_{\text {sim }}}$
The factor $10^{9}$ is used to show the obtained results in a more con venient way. The temperature difference between TC1 and TC8 has been chosen to be compared with the temperature results obtained in the experiment. The vertical temperature distribution has been con sidered as the most relevant phenomenon in the simulations due to the importance of this event in the operation of the IRWST, so that this parameter has been emphasized in the indicator to show its importance. The calculation of the simulation efficiency is shown in Table 4.

The simulation with the greater efficiency in the mesh sensitivity is the $\mathrm{ZcXa}$ case, with a score 7.12. It is followed by the $\mathrm{ZcXb}$ case, with a score of 5.89. The simulation efficiency in both cases is close, the $\mathrm{ZcXb}$ case has a finer mesh, higher temperature gradient and less average error. The main difference is the CPU required time and it gives the advantage to $\mathrm{ZcXa}$ simulation.

Regarding the discretization scheme, the simulation efficiency of all tested options is lower than the reference case, so it can be seen that the BSOUP method provides the most accurate results. Analyzing efficiency of the cases with the different turbulence models shows that the k $\varepsilon$ RG and the k $\varepsilon$ NL2 models give much better results than the k $\varepsilon$ STD used in the reference case. Regarding the wall heat transfer, the most efficient cases are the FLM ones, where the temperature gradient is good in all of them, and the computational time does not peak. It makes clear that the FILM model is more suitable for this experiment than the Direct with DLM FM model.

A case with the parameters with the higher score between each si mulation (discretization scheme, turbulence, and wall heat transfer) has been created from the reference case mesh (BSOUP, $k \varepsilon$ NL2, FILM MOUCHIDA). This case has been labelled as " $\mathrm{X}$ case" and an

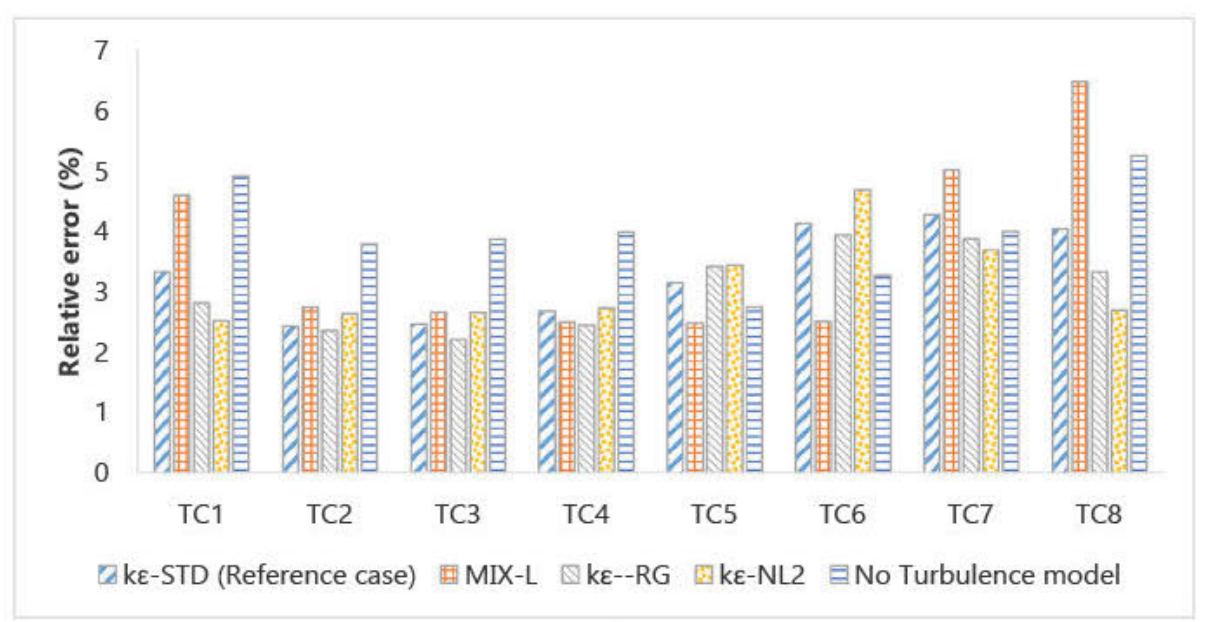

Fig. 15. Total average error for all turbulence models as defined in Eq. (5). 
Table 3

Heat transfer configurations of the channel wall.

\begin{tabular}{|c|c|c|c|c|c|c|}
\hline Case & & Reference case & Adiabatic & h GOTHIC & Internal & FILM \\
\hline HTC Type & & External & - & External & Internal & External \\
\hline \multirow[t]{3}{*}{ Inner Side } & Heat Transfer & Direct & - & Direct & Direct & Film \\
\hline & Wall condensation & DLM-FM & - & DLM-FM & DLM-FM & $\begin{array}{l}\text { Uchida/Mouchida/G-K/ } \\
\text { MAX }\end{array}$ \\
\hline & $\begin{array}{l}\text { Natural convection } \\
\text { option }\end{array}$ & $\begin{array}{l}\text { Vertical surface (Wall), face up } \\
\text { (bottom) }\end{array}$ & - & $\begin{array}{l}\text { Vertical surface (Wall), face } \\
\text { up (bottom) }\end{array}$ & $\begin{array}{l}\text { Vertical surface (Wall), face up } \\
\text { (bottom) }\end{array}$ & - \\
\hline \multirow[t]{2}{*}{ Outer Side } & Heat transfer & $\mathrm{h}=4.51 \mathrm{~W} / \mathrm{m}^{2} \mathrm{~K}$ & - & Direct & $\mathrm{h}=4.51 \mathrm{~W} / \mathrm{m}^{2} \mathrm{~K}$ & $\mathrm{~h}=4.51 \mathrm{~W} / \mathrm{m}^{2} \mathrm{~K}$ \\
\hline & Wall condensation & DLF-FM & - & DLF-FM & DLF-FM & DLF-FM \\
\hline
\end{tabular}

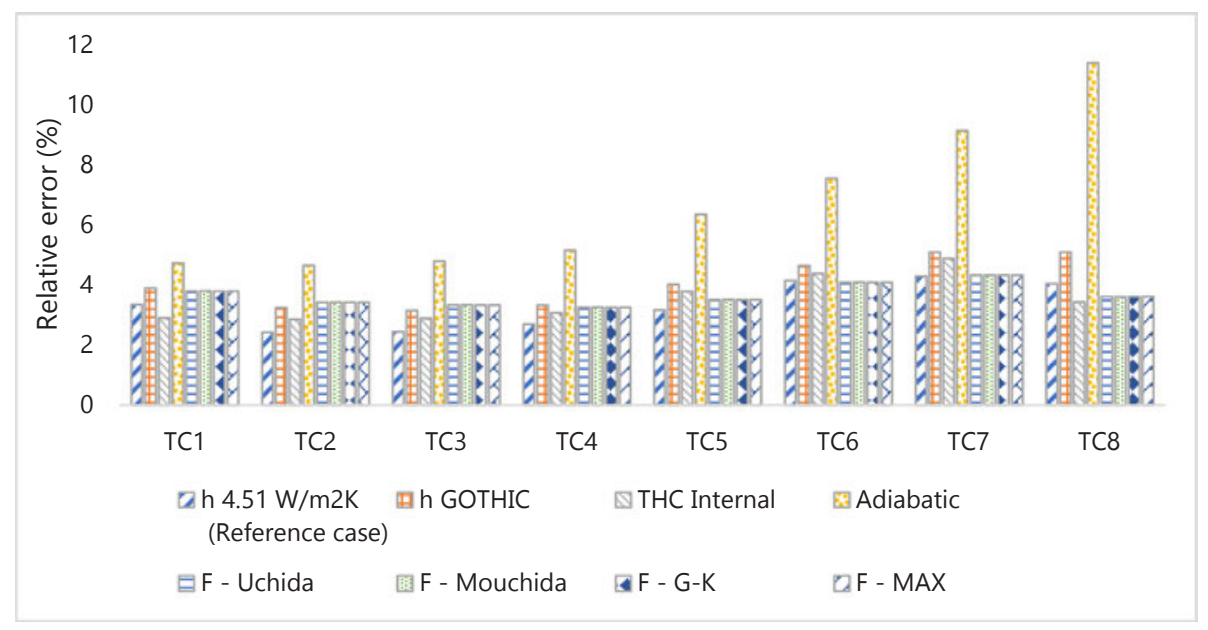

Fig. 16. Total average error for all heat transfer configurations on the channel wall (calculated according to Eq. (5)).

overview of the results of this case is shown in Table 4. The simulation efficiency of this case is not the best compared with the other cases, basically because there is a less pronounced vertical temperature dis tribution caused by the possible feedback in velocity between the tur bulence model (NL2) and the convection correlation used in the FILM model. However, the average error is close to the measured error and the void fraction distribution is similar to the experiment in the first stages.

\section{Conclusions}

An experimental facility was constructed to investigate the behavior of an AP1000 IRWST during ADS actuations. Steam was injected through a $4 \mathrm{~mm}$ nozzle at the bottom of the rig, producing similar steam exit velocities to those found in a real IRWST. Phenomena such as steam condensation, temperature gradient or flashing was reproduced ade quately. More complex phenomena, such as bubble columns formation or water mixing caused by the steam heating, relevant in the perfor mance of the IRWST, went beyond the scope of the experiment, as only a limited volume of the IRWST was modeled.

The experimental investigations provided experimental observa tions, time averaged $2 \mathrm{D}$ distributions of the projected void fraction distributions and temperature axial distributions during different stages of the experiment (different subcooling temperatures).

The obtained experimental data has been used to determine the optimal mesh size and set up in GOTHIC simulations of the tested case. The mesh size is sufficiently small to obtain closest comparable results with experimental data while not having an excessive computational cost, is of special interest for the modeling of an AP1000 full contain ment.

Regarding the fact that these simulations are obtained from a code that normally model the whole containment (a coarse mesh has to be applied) and that these are 2D simulations, the obtained agreement between results and experiment is correct. Nevertheless, this agreement can be further improved if a simulation of this channel alone with higher number of numerical cells was considered.

GOTHIC predicted the main phenomena identified in the experi ment, such as direct condensation of the steam, vertical temperature distribution and flashing successfully. The total average error obtained in the reference case is acceptable, considering the computational time and the coarse mesh compared with a CFD code. The steam fraction distribution differs from the postprocessed images obtained from the experiments, possibly because of the mesh size and the simplification made comparing these 3D images with 2D simulations, nonetheless the phenomenology development in the simulation is similar.

The obtained results show the importance of the selection of si mulation parameters. Parameters such as discretization scheme or mesh have a strong influence in the temperature distribution. The best results are achieved with a second order scheme and a finer mesh (between $0.01 \mathrm{~m}$ ), but it has to be considered that it is important to reach a balance between precision and simulation time, as the final goal is to use these results to decide the mesh size and settings for the IRWST in the AP1000 full containment model with GOTHIC, taking into account the limitations of the code regarding the number of cells $(<100 \mathrm{k}$ cells for GOTHIC 8.1).

\section{Acknowledgments}

This work has been funded by the Spanish Ministry of Competitiveness and Economy within PYGAS project: ENE2015 67638 $\mathrm{R}$ (MINECO/FEDER). Its support is gratefully acknowledged.

The author acknowledges the computer resources and technical assistance provided by the Centro de Supercomputación y Visualización de Madrid (CesviMa).

The authors want to express their deep gratitude to EPRI and NAI company personnel, especially Tom George and Jeff Lane, for their 
Table 4

Sensitivity simulation results. Simulation efficiency scores.

\begin{tabular}{llllll}
\hline Case & $\begin{array}{l}\text { Average } \\
\Delta \mathrm{T}[\mathrm{K}]\end{array}$ & $\begin{array}{l}\text { Total } \\
\text { average } \\
\text { error [\%] }\end{array}$ & $\begin{array}{l}\text { Flashing } \\
\text { time [s] }]\end{array}$ & $\begin{array}{l}\text { CPU } \\
\text { required } \\
\text { time [s] }\end{array}$ & $\begin{array}{l}\text { Simulation } \\
\text { Efficiency } \\
{[\eta]}\end{array}$ \\
\cline { 2 - 6 } Experiment & 10.26 & & 6000 & & \\
\hline ZaXa & 1.67 & 4.800 & 5338 & 2707 & 1.576 \\
ZaXb & 3.74 & 3.602 & 5314 & 1660 & 5.735 \\
ZaXc & 4.09 & 3.349 & 5326 & 48,200 & 0.241 \\
ZbXa & 1.56 & 4.503 & 5130 & 3567 & 0.946 \\
ZbXb & 5.24 & 4.416 & 5145 & 14,130 & 0.744 \\
ZbXc & 4.65 & 3.087 & 5337 & 54,810 & 0.283 \\
ZcXa & 6.147 & 3.924 & 5345 & 3230 & 7.120 \\
ZcXb & 7.16 & 3.302 & 5396 & 8844 & 5.899 \\
ZcXc & 5.78 & 3.207 & 5370 & 60,400 & 0.408 \\
ZdXa & 15.72 & 6.064 & 5300 & 28,900 & 0.273 \\
ZdXb & 16.49 & 6.637 & 5585 & 22,450 & 0.417 \\
ZdXc & 12.66 & 4.423 & 5450 & 198,000 & 0.360 \\
FOUP & 1.323 & 4.102 & 5330 & 4803 & 0.949 \\
MFOUP & 1.324 & 4.043 & 5323 & 15,970 & 0.287 \\
FLSOUP & 2.65 & 4.288 & 5378 & 6085 & 1.064 \\
k-e RG & 7.89 & 3.039 & 5643 & 22,080 & 7.432 \\
MIX-L & 4.55 & 3.610 & 5465 & 8318.8 & 1.909 \\
k-e NL2 & 9.14 & 3.120 & 5344 & 7990 & 48.748 \\
No turbulence & 7.11 & 3.960 & 5424 & 7517 & 5.878 \\
$\quad$ model & & & & & \\
Adiabatic & 5.77 & 6.705 & 4705 & 6026 & 0.948 \\
h GOTHIC & 7.55 & 4.038 & 5183 & 12,180 & 3.389 \\
THC internal & 8.43 & 3.499 & 5393 & 20,887 & 6.731 \\
FILM- & 8.16 & 3.647 & 5365 & 8021 & 12.189 \\
$\quad$ Mouchida & & & & & \\
FILM-Uchida & 8.16 & 3.645 & 5365 & 8162 & 11.986 \\
FILM-G-K & 8.16 & 3.645 & 5365 & 8515 & 11.493 \\
FILM-MAX & 8.16 & 3.645 & 5365 & 9818 & 9.967 \\
X case & 7.34 & 3.04 & 5425 & 9052 & 7.405 \\
\hline & & & & & \\
\hline
\end{tabular}

valuable technical support and help during the development this work.

\section{References}

Al Issa, S., Macian-Juan, R., Jimenez, G., Queral, C., Montero-Mayorga, J., 2015 Experimental investigation and flow visualization of steam condensation in a scaled IRWST-ADS simulator. In: NURETH-16. ANS, Chicago, USA, pp. 8562-8575.

Al Issa, S., Weisensee, P., Macián-Juan, R., 2014. Experimental investigation of steam bubble condensation in vertical large diameter geometry under atmospheric pressure and different flow conditions. Int. J. Heat Mass Transf. 70, 918-929. http://dx.doi. org /10.1016/j.ijheatmasstransfer.2013.11.049.

Analytis, G.T., 2001a. Implementation and Assessment of the Renormalization group (RNG) k-e model in GOTHIC. Nucl. Eng. Des. 210, 177-191. http://dx.doi.org/10. 1016/S0029-5493(01)00417-4.

Analytis, G.T., 2001b. Implementation and assessment of the renormalization group (RNG), quadratic and cubic non-linear eddy viscosity k-e models in GOTHIC. Nucl. Eng. Des. 210, 177-191. http://dx.doi.org/10.1016/S0029-5493(01)00417-4.

Andreani, M., Badillo, A., Kapulla, R., Smith, B., 2015. Syntehsis of the OECD/NEA-PSI CFD benchmark exercise, in: NURETH-16. Chicago, pp. 1787-1801.

Andreani, M., Paladino, D., 2010. Simulation of gas mixing and transport in a multicompartment geometry using the GOTHIC containment code and relatively coarse meshes. Nucl. Eng. Des. 240, 1506-1527. http://dx.doi.org/10.1016/j.nucengdes. 2010.02.020.

Andreani, M., Paladino, D., George, T., 2010. Simulation of basic gas mixing tests with condensation in the PANDA facility using the GOTHIC code. Nucl. Eng. Des. 240, 1528-1547. http://dx.doi.org/10.1016/j.nucengdes.2010.02.021.
Craft, T.J., Launder, B.E., Suga, K., 1996. Development and application of a cubic eddyviscosity model of turbulence. Int. J. Heat Fluid Flow 17, 108-115. http://dx.doi.org/ 10.1016/0142-727X(95)00079-6.

EPRI, 2014. GOTHIC Thermal Hydraulic Analysis Package, Version 8.1 (QA). Palo Alto, CA.

Fernández-Cosials, M.K., Jimenez, G., Lopez-Alonso, E., 2016. Analysis of a gas stratification break-up by a vertical jet using the GOTHIC code. Nucl. Eng. Des. 297, 123-135. http://dx.doi.org/10.1016/j.nucengdes.2015.11.035.

Gallego-Marcos, I., Villanueva, W., Kudinov, P., 2016a. Modeling of thermal stratification and mixing in a pressure suppression pool using GOTHIC (N11P0524), in: NUTHOS11. pp. 1-11.

Gallego-Marcos, I., Villanueva, W., Kudinov, P., Kapulla, R., Paranjape, S., Paladino, D., 2016b. Scaling and CFD modelling of the pool experiments with spargers performed in the PANDA facility, in: NUTHOS11. pp. 1-15.

Incropera, F.P., Bergman, T.L., Lavine, A.S., DeWitt, P.D., 2011. Fundamentals of Heat and Mass Transfer (7th edition). Seventh ed. United States of America.

Jimenez, G., Serrano, C., Lopez-Alonso, E., Molina, M., Del, C., Calvo, D., García, J., Queral, C., Zuriaga, J.V., González, M., 2015. BWR Mark III containment analyses using a GOTHIC 8.0 3D model. Ann. Nucl. Energy 85, 687-703. http://dx.doi.org/10. 1016/j.anucene.2015.06.025.

Kang, H., Song, C., 2008. CFD analysis of a thermal mixing in a subcooled water pool under a high steam mass flux. Nucl. Eng. Des. 238 (3), 492-501.

Kang, H.S., Song, C.H., 2010. CFD analysis of a turbulent jet behavior induced by a steam jet discharge through a single hole in a subcooled water tank. Nucl. Eng. Des. 240, 2160-2168. http://dx.doi.org/10.1016/j.nucengdes.2009.11.026.

Li, H., Kudinov, P., 2015. Effective approaches to simulation of thermal stratification and mixing in a pressure suppression pool, in: CFD4NRS-3: Experimental Validation and Application of CFD and CMFD Codes to Nuclear Reactor Safety Issues. Washington D. C., USA.

Li, H., Kudinov, P., 2009. GOTHIC code simulation of thermal stratification in POOLEX facility, NKS-196.

Li, H., Kudinov, P., Villanueva, W., 2010. Modeling of Condensation, Stratification, and Mixing Phenomena in a Pool of Water, NKS-225.

Li, H., Villanueva, W., Kudinov, P., 2014a. Approach and development of effective models for simulation of thermal stratification and mixing induced by steam injection into a large pool of water approach and development of effective models for simulation of thermal stratification and mixing induced. Sci. Technol. Nucl. Install. 2014, 1-11. http://dx.doi.org/10.1155/2014/108782.

Li, H., Villanueva, W., Kudinov, P., 2014b. Validation of effective models for simulation of thermal stratification and mixing induced by steam injection into a large pool of water. Sci. Technol. Nucl. Install. 2014, 1-19. http://dx.doi.org/10.1155/2014/ 108782.

Montero-Mayorga, J., Queral, C., Gonzalez-Cadelo, J., 2015. AP1000 SBLOCA simulations with TRACE code. Ann. Nucl. Energy 75, 87-100. http://dx.doi.org/10.1016/j. anucene.2014.07.045.

Moon, Y.T., Lee, H.D., Park, G.C., 2009. CFD simulation of steam jet-induced thermal mixing in subcooled water pool. Nucl. Eng. Des. 239, 2849-2863. http://dx.doi.org/ 10.1016/j.nucengdes.2009.08.003.

Nordic Nuclear Safety Research (NKS), n.d. Nordic Nuclear Safety Research webpage [WWW Document]. URL http://www.nks.org/en/.

Ozdemir, O.E., George, T.L., 2015. BWR MARK I pressure suppression pool mixing and stratification analysis using GOTHIC lumped parameter modeling methodology. Ann. Nucl. Energy 85, 532-543. http://dx.doi.org/10.1016/j.anucene.2015.06.006.

Ozdemir, O.E., George, T.L., Marshall, M.D., 2015. Fukushima Daiichi Unit 1 power plan containment analysis using GOTHIC. Ann. Nucl. Energy 85, 621-632. http://dx.doi. org/10.1016/j.anucene.2015.06.017.

Papadakis, G., Bergeles, G., 1995. A locally modified second order upwind scheme for convection terms discretization. Int. J. Numer. Methods Heat FLluid Flow 5, 49-62.

Pättikangas, T., Niemi, J., Timperi, A., 2009. Modelling of Blowdown of Steam in the Pressurized PPOOLEX Facility (NKS-209)

Speziale, C.G., Gatski, T.B., 1990. Modeling the Pressure-strain Correlation of TurbulenceAn Invariant Dynamical Systems Approach. Langley.

Timperi, A., Pättikangas, T., Niemi, J., Ilvonen, M., 2006. Fluid-Structure Interaction Analysis of a Water Pool under Loading Caused by Steam Injection (NKS-127).

Ayachit, Utkarsh, 2015. The Paraview Guide. Kitware Inc.

Villanueva, W., Li, H., Puustinen, M., Kudinov, P., 2015. Generalization of experimental data on amplitude and frequency of oscillations induced by steam injection into a subcooled pool. Nucl. Eng. Des. 295, 155-161. http://dx.doi.org/10.1016/j. nucengdes.2015.08.031.

Westinghouse Electric Company LLC, 2009. AP1000 Design Control Document, in AP1000 Design Control Document 3. pp. 1-2.

Yakhot, V., Orszag, S.A.S.A., 1986. Renormalization group analysis of turbulence. I. Basic theory. J. Sci. Comput. 1, 3-51. http://dx.doi.org/10.1007/BF01061452. 